AHP/ANP theory and its application in technological and economic development. The 90th anniversary of prof. Thomas I. Saaty

\title{
COMBINING DRSA DECISION-RULES WITH FCA-BASED DANP EVALUATION FOR FINANCIAL PERFORMANCE IMPROVEMENTS
}

\author{
Kao-Yi SHENª, Gwo-Hshiung TZENG ${ }^{\mathrm{b}}$ \\ ${ }^{a}$ Department of Banking and Finance, Chinese Culture University (SCE), Taipei 11114, Taiwan \\ ${ }^{b}$ Graduate Institute of Urban Planning, College of Public Affairs, National Taipei University, \\ 151, University Rd., San Shia District, New Taipei City 23741, Taiwan
}

Received 13 March 2014; accepted 15 November 2014

\begin{abstract}
This study proposes a combined method to integrate soft computing techniques and multiple criteria decision making (MCDM) methods to guide semiconductor companies to improve financial performance (FP) - based on logical reasoning. The complex and imprecise patterns of FP changes are explored by dominance-based rough set approach (DRSA) to find decision rules associated with FP changes. Companies may identify its underperformed criterion (gap) to conduct formal concept analysis (FCA) - by implication rules - to explore the source criteria regarding the underperformed gap. The source criteria are analysed by decision making trial and evaluation laboratory (DEMATEL) technique to explore the cause-effect relationship among the source criteria for guiding improvements; in the next, DEMATEL-based analytical network process (DANP) can provide the influential weights to form an evaluation model, to select or rank improvement plans. To illustrate the proposed method, the financial data of a real semiconductor company is used as an example to show the involved processes: from performance gaps identification to the selection of five assumed improvement plans. Moreover, the obtained implication rules can integrate with DEMATEL analysis to explore directional influences among the critical criteria, which may provide rich insights and managerial implications in practice.
\end{abstract}

Keywords: dominance-based rough set approach (DRSA), formal concept analysis (FCA), decision making trial and evaluation laboratory (DEMATEL), multiple criteria decision making (MCDM), DEMATEL-based ANP (DANP), financial performance (FP).

JEL Classification: C18, C38, C61, C82.

\section{Introduction}

In recent years, the intensification of competitions in the global supply chain and rapid changes in economic environment has caused more challenges for companies to maintain or improve its financial performance (FP) with clear guidance. As a result, the importance

Corresponding author Gwo-Hshiung Tzeng

E-mail: ghtzeng@gm.ntpu.edu.tw 
of using advanced and analytical techniques to support financial decision making has been aware in both academic and practical fields (Spronk et al. 2005). Considering the complexity among the involved factors of FP, the multiple criteria decision making (MCDM) approach is suitable and widely explored to tackle this issue (Steuer, Na 2003; Xidonas et al. 2009). Moreover, certain computational intelligence techniques (e.g., fuzzy logics, rough set approach, and artificial neural network) that may deal with the uncertain and imprecise characteristics of business information are incorporated to enhance the effectiveness of models. A rising trend to integrate multiple methods (or techniques) based on the strengths of each method (or technique) has emerged, and the present study also attempts to devise an integrated model for FP prediction and diagnosis in this approach.

The study of FP has caused increasing interests from various groups (e.g., investors, creditors, and management teams) for at least three purposes: (a) find out a company or stock with investment potential; (b) detect early signs of insolvency; (c) pursue the right direction for conducting improvement plans (Penman 2007). Due to its potential value and practical needs from business environment, researchers from various fields have tried to address this research topic. Conventional studies mainly rely on statistical analyses to identify the main variables that have positive or negative influences on future FP (Piotroski 2000). However, the most often used statistical model - regression model - has obvious limitations in several aspects. For example, the prerequisite linear relationship of the regression model is not realistic; also, the assumed independence among the considered variables might not be valid. In a real world, factors are often interrelated with certain relationships (Liou, Tzeng 2012). To extend the limitations of conventional studies, various multiple criteria decision making (MCDM) and computational intelligence methods have been tried to explore the FP prediction problem. The commonly used MCDM methods - such as Analytic Hierarchy Process (AHP) (Saaty 1988), Analytic Network Process (ANP) (Saaty 2004), DEMATEL (Gabus, Fontela 1972) and TOPSIS (Opricovic, Tzeng 2004) - collect domain expert's opinions to decide the influential weights of each criterion for ranking and selecting company with plausible superior FP in the future. Enhanced from AHP, the ANP method (Saaty 2004) was proposed to consider the dependence relationship among criteria, and integrate multiple dimensions and criteria for making complex decisions. However, this kind of MCDM models depend on the subjective judgments of domain experts, criticized by lacking of objective supports. On the contrary, computational intelligence techniques or methods depend on advanced algorithms to induct (explore) the implicit patterns from large data sets. The well-known artificial neural network (ANN) (Lam 2004; Shen 2011), neuro-fuzzy inference technique (Boyacioglu, Avci 2010), decision tree (DT) (Wang, Chan 2006), rough set approach (RSA) (Shyng et al. 2010a), all have been applied to solve this FP prediction problem. The ANN related techniques have strength in minimizing its modeling errors through various learning algorithms; nevertheless, the implicit knowledge is embedded in its connections among nodes and its network structure, difficult for gaining reusable and understandable knowledge. Compared with ANN related techniques, DT and RSA methods could induct understandable decision rules; nevertheless, these induction methods mainly process discretized inputs (i.e., transform numerical data into intervals or rankings) to capture certain granule of knowledge, which have limitations in exploring the interrelationship among the criteria and gaining more managerial implications. Both MCDM meth- 
ods and computational intelligence techniques have their own strengths and limitations; thus, a logical combination that may capture the changes of FP patterns from large data sets and clarify the interrelationship among the critical criteria is highly needed in practice.

Aside from the FP prediction problem, once a company was classified as underperforming in the next period, which direction (criterion) it should focus to improve at the current stage - based on limited resources - is another important issue. Furthermore, the involved criteria are often interrelated in a real business environment (Liou, Tzeng 2012), and how to consider the plausible directional influences to design or evaluate an improvement plan for a specific criterion is still unexplored. To bridge the gap, this study plans to design an FP diagnosis model by infusing two approaches: computational intelligence and MCDM methods. To be more accurate, this study aims to answer the following questions for supporting decision makers in a real business environment: Which criteria are crucial to identify the changes of FP? Once a company found the critical gap that it plans to improve, which are the relevant criteria that should be considered in a contextual way? Moreover, if the company came out with several improvement plans for its identified gap (certain criterion), how to select among the potential improvement plans? To answer the aforementioned questions, a Dominance-based Rough Set Approach (DRSA) (Greco et al. 2002 ) is proposed to explore the patterns of FP changes. DRSA is extended from RSA (Pawlak 1982), which considers preferential characteristic of criteria while making inductions. The evaluation of FP involves various financial attributes, and those attributes often have preferential characteristic in nature; for example, the higher gross margin ratio is generally preferred concerning FP evaluation. The obtained decision rules from DRSA may support underperformed companies to identify performance gaps for improvements; however, if a company further attempts to devise or select improvement plans for its performance gaps, a logical and systematic evaluation method is still required. As a result, the present study proposes an FCA-based MCDM model in the next stage, to extend the findings from the DRSA decision rules.

At the second stage, if a criterion was targeted to improve, it is necessary to identify its highly interrelated criteria to plan for improvements; otherwise, it might cause unwanted side-effects while implementing a new plan. To meet this goal, a formal concept analysis (FCA)-based DANP (DEMATEL-based ANP) analysis (Shen, Tzeng 2015) is proposed for the diagnosis. FCA is a mathematical theory (Wille 2005), which may induct from historical data to generate implication rules and pertinent criteria in a logical approach. Finally, the associated criteria could be analyzed (by DANP model) to explore the directional influences and relative weights concerning the improvement of the addressed target (criterion). The simplified two-stage research flow is illustrated as Figure 1. (detail steps will be provided in Section 3).

Compared with previous studies that applied MCDM (Spronk et al. 2005; Zopounidis, Doumpos 2013) or computational intelligence techniques (Bahrammirzaee 2010) for FP problems, the present study has three major differences as below:

1) Most of previous research put emphasis on prediction/classification (by using computational intelligence techniques) or ranking/selection (by MCDM) methods; however, the present study focuses on FP improvement planning, which has constructive managerial implications for companies (Liou, Tzeng 2012); 


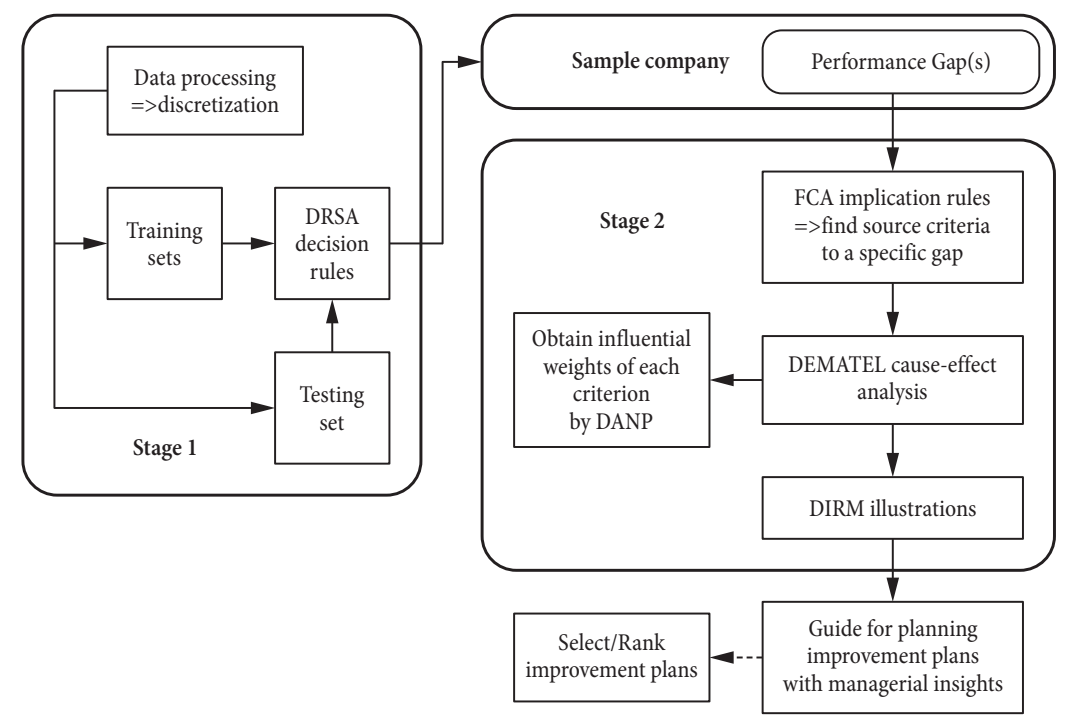

Fig. 1. Two-stage research flows (Guide/Select/Rank FP improvement plans)

2) To our best knowledge, this study is the first model that attempts to devise a MCDM evaluation model (i.e., DANP) based on FCA implications, to support a systematic improvement planning for an individual company;

3) While nearly all previous MCDM methods attempted to construct a model for ranking or selection - for all alternatives (including new companies), the proposed approach aims to support an individual company to devise an evaluation model based on its current performance gap, to select the best improvement plan.

The remainder of this study is structured as below: Section 1 provides a discussion regarding the FP prediction problem and the involved research methods, including DRSA, FCA, DEMATEL, and DANP. In Section 2, the proposed two-stage model is explained with needed steps. Section 3 takes the public-listed semiconductor stocks in Taiwan as an empirical case for examining the proposed model. The research results and discussions are included in Section 4, and the final section concludes this study with suggested future research directions.

\section{Preliminary of DRSA rules with FCA-based DANP evaluation}

This section briefly reviews the MCDM methods applied to deal with financial problems. In addition, the combined methods (i.e., DRSA, FCA, and DANP) are discussed, with the main purposes for adopting each method and technique, and the advantages compared with previous studies are also discussed. 


\subsection{Multiple criteria decision making (MCDM) methods in finance}

The growing complexity in the business environment has raised the needs to evaluate financial decisions considering multiple aspects and criteria; therefore, it is well-suited to adopt various methods in the framework of MCDM for solving financial problems (Spronk et al. 2005; Zopounidis, Doumpos 2013). The aforementioned financial problems could be roughly divided into two categories: investment analysis (e.g., portfolio management and investment evaluation) and corporate finance (e.g., FP prediction and evaluation, business failure prediction, capital budgeting, credit scoring, auditing, and financial planning), and the present study belongs to the latter category.

In practice, the use of financial ratios for comparing and forecasting the FP of a company is commonly adopted, also termed as fundamental analysis (FA). FA is generally conducted by comparing the relative FP of a company within its industry (i.e., with its peer group) or modeling the patterns of its own FP indicators over a period of time (Penman 2007). In financial studies, FA is mainly modeled by regressions; however, the unrealistic assumptions (such as the independence of the involved variables, the linear relationship among the target variable and the other involved variables) of regression models might cause unpersuasive results. Furthermore, regression represents the "average" result (Spronk et al. 2005), which has difficulty in indicating the contingent performance in a specific context. On the other side, certain MCDM methods do not have the limitations to assume the probabilistic distributions of variables and the independence among the criteria (e.g., ANP and DANP), which are more realistic in practice. As a result, MCDM methods have strengths to complement the existing financial research to solve FP problems (Liou, Tzeng 2012).

To consider multiple aspects simultaneously, several MCDM outranking methods have been introduced to assess the FP of companies, such as the two groups of outranking methods: ELECTRE (Ergul, Oktem 2011) and PROMETREE (Mareschal, Brans 1991; Mareschal, Mertens 1992; Tsui et al. 2014). Another main stream in MCDM is the utilitybased approach, such as multi-attribute utility theory (MAUT) (Diakoulaki et al. 1992; Tzeng et al. 1989; Yeh et al. 2000), and utility additive method (UTA) (Zopounidis et al. 1995). The utility-based theory has its theoretical foundation in economics to aggregate the preferences of decision maker (DM) on multiple attributes. The aforementioned outranking methods and utility-based approach may conduct ranking and selection without the prerequisite assumption of the probabilistic distribution of variables. Nevertheless, they still assume the independent relationship among criteria (Liou, Tzeng 2012; Liou 2013; Peng, Tzeng 2013); in addition, they are insufficient to support for FP improvements.

Recently, AHP extended methods (i.e., ANP and DANP) have been adopted to resolve the FP evaluation problem (Shen et al. 2014; Shen, Tzeng 2014b). This approach requests domain experts (or DMs) to make pairwise comparison between two criteria in each other, and the relative influence of each criterion may be obtained to form the overall performance evaluation model. More detailed discussions on this approach will be provided in Subsection 1.4. Although this approach may allow for interdependence among criteria (i.e., ANP and DANP), the selection of criteria relies on subjective judgment. Considering 
the complexity of FP evaluation, how to select the minimal criteria (variables) with discernibility for modeling is still unanswered in this approach. Therefore, the present study adopts FCA (Shyng et al. 2010a; Ou Yang et al. 2011) implication analysis to find the highly related criteria - for the identified performance gap based on DRSA decision rules - from historical data, which could form the basis for the subsequent decision model in a more objective way.

\subsection{Rough set approach (RSA) for predicting financial performance}

RSA is a mathematical theory (Pawlak 1982), which has been implemented on various applications to deal with the imprecise and uncertain characteristic of data sets. Several studies had attempted to apply RSA for FP predictions, which could be categorized into two types: 1) a single RSA model implemented by different induction algorithms (Dimitras et al. 1999; Beynon, Peel 2001; Tay, Shen 2002); and 2) a hybrid or a combined model to infuse two or more techniques with RSA, such as ANN (Ahn et al. 2000), data envelopment analysis (DEA) (Shuai, Li 2005), and the rough-AHP with a fuzzy decision model (Aydogan 2011). The first type model employed RSA algorithms to induct rules from data sets, and the obtained rules were used to make classification or prediction. Though this type of RSA models gained positive results, it could not support an individual company to plan for improvements. The second type of model was devised with different purposes. The combination (Ahn et al. 2000) used RSA as a preprocessor to remove redundant attributes, and the ANN was applied to increase the model's accuracy. However, the ANN technique is criticized by its black-box processing (Ravi et al. 2008), the obtained knowledge was mainly stored in the network structure and the connections between nodes; DMs would have difficulties to gain understandable insights. The integration of RSA and DEA (Shuai, Li 2005) was done by using RSA to handle qualitative attributes (e.g., change of auditor) and using DEA to deal with quantitative attributes (e.g., financial ratios), and those two sub-modules were integrated in the next stage. Nevertheless, just like certain regression models, DEA is based on the assumptions of independence among variables and the linearity of a model; which is not that realistic in practice. The last model discussed here - the rough-AHP with a fuzzy decision model (Aydogan 2011) - integrated RSA with MCDM methods to make selection. The conditional entropy and attribute significance concepts in RSA were used to improve the judgment consistency in AHP. Nevertheless, the AHP method cannot evaluate the interdependence among attributes, which is also unable to support for improvement planning.

As for DRSA (Greco et al. 2002) adopted in this study, it was extended from classical RSA. DRSA was proposed to consider the preferential characteristic of attributes while making classification, which is more suitable to tackle multiple criteria decision problems. DRSA has at least six advantages in solving MCDM problems: 1) the considered preferential characteristic of conditional attributes is commonly required for evaluating performance; 2) generate intuitive and easy-to-understand decision rules to indicate findings; 3) capable to discern complex patterns with reduced variables; 4) does not need to assume the probability distributions of the examined data or variables; 5) able to deal with both quantitative 
and qualitative information and with interrelated criteria; 6) does not require discretization of quantitative criteria. Recently, the strengths of DRSA have been aware in the social science (Liou, Tzeng 2010; Shyng et al. 2010b; Zaras 2011; Shen, Tzeng 2014, 2015), and the aforementioned four advantages are also the reasons why this study adopts DRSA to explore the patterns of FP changes for the semiconductor companies. Applying DRSA decision rules for improvements might not be a new idea, the previous study (Greco et al. 2005) had proposed a system to estimate the plausible effects or improvements brought by taking a specific treatment to satisfy certain decision rule (or rules). Nevertheless, this approach assumed that the corresponding treatment was already known, and it would cause the same effect on all alternatives. On the contrary, the present study assumed that the improvement plans for each company should be different, which need to consider the resources and constraints of each company. Therefore, the present study attempts to explore FP patterns by DRSA at the first stage, and supports an individual company to identify the criteria associated with its underperformed criterion (by FCA) in the next stage; in addition, the proposed model may explore the cause-effect relationship (by DEMATEL analysis) among the considered criteria to guide for systematic improvements and select improvement plans (integrated-weighting by DANP) based on influential network relationship map (INRM), which are the major differences and the novelty compared with previous RSA applications.

\subsection{Formal concept analysis (FCA) for obtaining implication rules}

FCA is originated from applied mathematics, rooted from lattice theory (Ganter et al. 1997; Wille 2005). The FCA analysis can organize objects and related attributes in a contextual approach to form hierarchical concept lattices, with the capability to clarify the formalization of concept with implication rules. The applications of FCA have gained increasing interests in international research community recently, and the applications ranges from software engineering, knowledge discovery, marketing (Fang et al. 2012), personal investment portfolios (Shyng et al. 2010a), and information retrieval (Tilley et al. 2005). The use of FCA in financial application such as investment analysis or performance evaluation is relatively underexplored. The use of FCA could support to explore the related source criteria of a specific financial attribute in a logical approach, and we attempt to construct a persuasive model based on FCA implications to select the critical attributes in DANP model.

\subsection{DEMATEL and DEMATEL-based ANP (DANP)}

In social science research, most of the involved variables have interrelationship in a complex problem, and DEMATEL technique (Gabus, Fontela 1972) was proposed to evaluate the total influences and entwined relations among the considered criteria (Ou Yang et al. 2008, 2013; Liou, Tzeng 2012; Peng, Tzeng 2013). Compared with conventional regression models, DEMATEL does not need to assume the independence of the considered variables (criteria); furthermore, it may divide the criteria into a cause group and an effect group, and the directional influences (from cause group to effect group) could thus be explored. 
The obtained directional influences may support decision makers to gain more indepth understanding of the addressed problem. The use of DEMATEL has been widely incorporated into various applications, such as the vendor or supplier selection problem (Hsu et al. 2012), forming strategy map (Jassbi et al. 2011), explore the core competences of IC design service companies (Lin et al. 2011), and the examination of hospital service quality (Tseng 2009).

Aside from finding the directional influences among criteria, DEMATEL technique was also integrated with the well-known MCDM evaluation method - analytic network process (ANP), to adjust the weights of the involved dimensions in an evaluation model (Yang, Tzeng 2011), also termed as DANP. This hybrid MCDM approach has gained increasing interests in many social science studies recently, such as the security risk control assessment (Ou Yang et al. 2013), the selection of outsourcing provider (Hsu et al. 2013), the stock investment problem (Shen et al. 2014), and exploring smart phone improvements (Hu et al. 2012, 2014). In this study, to leverage the analytical capability of DEMATEL (explore the directional influences among criteria) and DANP (find out the influential weights of criteria for improving a target criterion), the results of DEMATEL will be integrated with FCA implication rules for forming the directional implication relationship map (DIRM), and the DIRM may thus support DMs to plan for improvements by identifying the source influences of underperformed criteria. As a result, DMs may plan in a systematic way to prevent from only focusing on the identified performance gap.

\section{Research model}

This section provides the essential ideas of the applied methods in this study, and the required steps for the proposed model are also discussed. The proposed model comprises of three parts: 1) Induct decision rules for classifying future FP; 2) Obtain implication rules and source criteria for the addressed performance gap; 3) Construct DANP model for evaluating and selecting improvement plans.

\subsection{Dominance-based rough set approach (DRSA)}

DRSA begins with an information table, and instance (objects) can be placed in rows with attributes in columns. Compared with classical RSA, the main difference of DRSA is the consideration of ordinal evaluation of objects and attributes. The typical data table of DRSA comprises of four tuples, which can be indicated as an information system (IS), for $I S=(U, Q, V, f)$. In the DRSA IS, $U$ is a finite set of universe, $Q$ is a finite set of $k$ attributes (i.e., $Q=\left\{q_{1}, q_{2} \ldots, q_{k}\right\}$ ), $V$ is the value domain of attribute (i.e., $V=\bigcup_{q \in Q} V_{q}$ ), and $f$ denotes a total function (i.e., $f: U \times Q \rightarrow V$ ). The attributes comprise of condition attributes $C$ and decision attribute $D$ in a typical DRSA model, and the conditional attributes are often regarded as criteria for a MCDM evaluation problem.

Suppose that there are $n$ objects in $U$, a complete outranking relation on $U$ can be defined as $\succeq_{q}$ with respect to a criterion $q \in Q$; if $x \succeq_{q} y$ for $x, y \in U$, then it denotes that 
" $x$ is at least as good as $y$ with respect to criterion $q$ ". In DRSA, the outranking relation $\succeq_{q}$ is generally supposed to be a complete preorder relation with respect to criterion $q$. Decision attribute $d \in D$ divides $U$ into a finite number of decision classes (such as $m$ decision classes), i.e., $C l=\left\{C l_{t}: C l_{1}, C l_{2}, \ldots, C l_{m}\right\}$ for $t=1,2, \ldots, m$. For each $x \in U$, object $x$ belongs to only one class $\mathrm{Cl}_{t}\left(\mathrm{Cl}_{t} \in \mathrm{Cl}\right)$. Assume that $\mathrm{Cl}$ has preferential order (i.e., for all $r, s=1, \ldots, m$, if $r \succ s$, the decision class $C l_{r}$ is preferred to $C l_{s}$ ), an downward union $C l_{t}^{\leq}$and upward union $\mathrm{Cl}_{t}^{\geq}$of classes can be defined as Eq. (1)-(2):

$$
\begin{aligned}
& C l_{t}^{\leq}=\bigcup_{s \leq t} C l_{s} ; \\
& C l_{t}^{\geq}=\bigcup_{s \geq t} C l_{s} .
\end{aligned}
$$

The upward union is used in this study to identify the good decision class (i.e., positive FP change in the next period); therefore, only the upward union of classes is discussed hereafter. The condition attributes (criteria) can be used to classify decision classes by dominance relations. Given a set of attributes $P \subseteq C$ and $x, y \in U, x$ dominates $y$ with respect to set of attributes $P$ could be denoted by $x D_{P} y$ to represent $x P$-dominates $y$. Therefore, a set of objects (instances) dominating $x$ is termed as $P$-dominating set in Eq. (3), and a set of objects dominated by $x$ is called $P$-dominated set in Eq. (4):

$$
\begin{aligned}
& D_{P}^{+}(x)=\left\{y \in U: y D_{P} x\right\} ; \\
& D_{P}^{-}(x)=\left\{y \in U: x D_{P} y\right\} .
\end{aligned}
$$

The $P$-dominating set and $P$-dominated set can be used to representing a collection of upward and downward unions of decision classes, which may represent granules of knowledge. The $P$-lower and $P$-upper approximation of an upward union with respect to $P \subseteq C$ can be defined by Eq. (5) and Eq. (6) respectively:

$$
\begin{aligned}
& \underline{P}\left(C l_{t}^{\geq}\right)=\left\{x \in U: D_{P}^{+}(x) \subseteq C l_{t}^{\geq}\right\} ; \\
& \bar{P}\left(C l_{t}^{\geq}\right)=\left\{x \in U: D_{P}^{-} \cap C l_{t}^{\geq} \neq \varnothing\right\} .
\end{aligned}
$$

The $P$-lower approximation $\underline{P}\left(C l_{t}^{\geq}\right)$denotes all of the objects $x \in U$ that are for sure to be included in the upward union $C l_{t}^{\geq}$, whereas all objects have at least the same or better evaluation with regard to all criteria $P \subseteq C$. With the $P$-upper approximation and $P$-lower approximation of $C l_{t}^{\geq}$, the $P$-boundary of $C l_{t}^{\geq}$is defined as Eq. (7):

$$
B n_{P}=\bar{P}\left(C l_{t}^{\geq}\right)-\underline{P}\left(C l_{t}^{\geq}\right) \text {. }
$$

The so-called dominance principle requires that if an object $x$ dominating object $y$ on all considered criteria $P \subseteq C$ (i.e., in conditional part), then the object $x$ should also dominate $y$ on the decision attribute. The objects that comply with the dominance principle are called consistent; otherwise, inconsistent. Moreover, the quality of approximation is defined as the ratio in Eq. (8), and the ratio $\gamma_{P}(\mathrm{Cl})$ can be regarded as a consistency ratio, for all the objects from $U$ and all considered condition attributes $P \subseteq C$. 


$$
\gamma_{P}(C l)=\frac{\left|U-\left(\bigcup_{t \in\{2, \ldots, n\}} B n_{P}\left(C l_{t}^{\geq}\right)\right)\right|}{|U|} .
$$

Furthermore, the accuracy of approximation of ordered classes $C l_{t}^{\geq}$with regard to a set of criteria $P \subseteq C$ is defined as $\alpha_{P}\left(C l_{t}^{\geq}\right)$in Eq. (9), and $|\cdot|$ in Eq. (8)-(9) is the cardinality of a set.

$$
\alpha_{P}\left(C l_{t}^{\geq}\right)=\frac{\left|\underline{P}\left(C l_{t}^{\geq}\right)\right|}{\left|\bar{P}\left(C l_{t}^{\geq}\right)\right|} .
$$

Each minimal subset $P \subseteq C$ that may satisfy $\gamma_{P}(C l)=\gamma_{C}(C l)$ is called a REDUCT of $\mathrm{Cl}$, and the intersection of all REDUCTs represent the indispensable attributes to maintain the quality of approximation, called $\mathrm{CORE}_{\mathrm{Cl}}$. Using the dominance-based approximation approach, a set of decision rules can be obtained in the form of "if antecedent then consequence", which can support DMs to identify a company's performance gaps on the critical criteria (financial indicators) in decision rules, to plan for improvements for its FP. The DRSA decision rules comprise of two types: certain and possible; the certain decision rules provide conditions for objects belonging to $\underline{P}\left(\mathrm{Cl}_{t}^{\geq}\right)$, mainly used in this study. The details of DRSA can be found in (Greco et al. 2001, 2002; Błaszczyński et al. 2007, 2013). To conduct DRSA modeling in this study, the required steps are as below:

Step 1. Define condition attributes and decision attribute of a semiconductor stock, and conduct a three-level discretization for all the attributes, i.e., including condition attributes and decision attribute. The three-level discretization may deliver more intuitive understanding for DMs to interpret obtained decision rules by comparing the relative performance of a company with its peer group on each criterion. The details of the used three-level discretization in this study will be explained in Subsection 3.1.

Step 2. Match the values of a stock's condition attributes in time period $(t-1)$ with its decision class in time period $t$ to denote an object (instance), and the matched data set is devised to predict the FP of a stock in the subsequent period by using its current financial data.

Step 3. Construct DRSA model and obtain decision rules to identify stocks with plausible good FP in the next period. The validation of DRSA model will be further illustrated in Section 3.

\subsection{Formal concept analysis (FCA)}

Originated from applied mathematics, FCA was developed based on mathematical order and lattice theory, which has been applied in various fields, such as software engineering, knowledge acquisition, medical classification, and financial investment. FCA can be defined as a set of structure $\mathfrak{R}:=(G, M, I)$, and $I$ denotes the binary relation between two sets: $G$ and $M$. The elements in the set $G$ represent objects, and the elements in the set $M$ denote 
attributes. Thus, a formal context can be formed by connecting the objects in $G$ to attributes in $M$ through the binary relation $I$ (yes or no), i.e., $(g, m) \in I$ for $g \subseteq G$ and $m \subseteq M$. If $g=m^{I}$ and $m=g^{I}$; then $g$ and $m$ can be called the extent and intent of a pair of formal concept ( $g$, $m$ ). Based on the theorem in concept lattice (Ganter et al. 1997), while the concept lattice of $(G, M, I)$ is a complete lattice, it should be made up of the closed subsets (i.e., sub-lattices). The closed subset property provides the foundation for calculating Duquenne-Guigues base of implications, which has a minimal number of implication rules. In this study, the identified performance gap on a certain criterion can be regarded as a $m$ in the attribute set $M$, and the Duquenne-Guigues implication rules (Ganter et al. 1997; Wille 2005) can be obtained to explore the extents with high object supports.

Step 4. Examine a target company's performance on the strong decision rules (associated with good FP change in the subsequent period), and identify the top performance gap.

Step 5. Conduct Duquenne-Guigues implication reasoning in FCA to obtain implication rules associated with the source criteria that might lead to the identified performance gap attribute in Step 4.

With FCA implication analysis, decision makers could have a guidance regarding the source factors (criteria) related to the underperformed criterion (identified by DRSA decision rules) for a company. In a real business environment, the criteria regarding a company's FP are often interrelated; the FCA is proposed to induct from positive alternatives in the historical data, for finding the source criteria of the underperformed criterion for an individual company.

\subsection{DEMATEL-based analytic network process (DANP)}

After identify the pertinent criteria for evaluating improvement plans by FCA implication analysis, the obtained source criteria can be used to devise a questionnaire to collect domain expert's opinions regarding the relative importance of each criterion for evaluating an improvement plan. Because DEMATEL technique may support to explore directional relationship among dimensions (also attributes), the DANP is adopted in this study to construct the improvement evaluation model at the final stage.

Step 6. Calculate the direct-influence matrix $\boldsymbol{D}$ using performance scores from the initial average matrix $\boldsymbol{A}$.

Experts are asked to judge the direct effect that they feel attribute (criterion) $i$ will have on attribute (criterion) $j$, indicated as $a_{i j}$. The scale ranges from 4 (very high influence) to 0 (no influence). The initial average matrix takes the arithmetic mean of each expert's feedback for forming the initial average matrix $\boldsymbol{A}$ as Eq. (10):

$$
\boldsymbol{A}=\left[\begin{array}{ccccc}
a_{11} & \cdots & a_{1 j} & \cdots & a_{1 n} \\
\vdots & & \vdots & & \vdots \\
a_{i 1} & \cdots & a_{i j} & \cdots & a_{i n} \\
\vdots & & \vdots & & \vdots \\
a_{n 1} & \cdots & a_{n j} & \cdots & a_{n n}
\end{array}\right] .
$$


The direct influence matrix $\boldsymbol{D}$ can be obtained by normalize the initial average matrix $\boldsymbol{A}$ referring to Eq. (11)-(12):

$$
\mathbf{D}=k A
$$

$$
k=\min \left\{\frac{1}{\max _{i} \sum_{j=1}^{n} a_{i j}}, \frac{1}{\max _{j} \sum_{i=1}^{n} a_{i j}}\right\}, i, j \in\{1,2, \ldots, n\} .
$$

The total influence matrix $\boldsymbol{T}$ can be decomposed as Eq. (13), while $w \rightarrow \infty, \boldsymbol{D}^{w}=[0]_{n \times n}$, and $\boldsymbol{I}$ denotes the identity matrix in Eqs (13)-(14).

$$
\begin{gathered}
\boldsymbol{T}=\boldsymbol{D}+\boldsymbol{D}^{2}+\ldots+\boldsymbol{D}^{w}=\boldsymbol{D}\left(\boldsymbol{I}-\boldsymbol{D}^{w}\right)(\boldsymbol{I}-\boldsymbol{D})^{-1} \\
\boldsymbol{T}=\boldsymbol{D}(\boldsymbol{I}-\boldsymbol{D})^{-1}=\left[t_{i j}\right]_{n \times n}, \text { when } \lim _{w \rightarrow \infty} \boldsymbol{D}^{w} \cong[0]_{n \times n} .
\end{gathered}
$$

Step 7. Analyze the cause-effect results of each criterion and dimension, and use the dimensional weights from DEMATEL to adjust the un-weighted super-matrix in ANP, to obtain the influential weights of DANP (DEMATEL-based ANP) for each criterion.

The sum of rows and the sum of columns in the total-influence matrix $T$ can be formed as two vectors, which are $r=\left[\sum_{j=1}^{n} t_{i j}\right]_{n \times n}=\left(r_{1}, \ldots, r_{i}, \ldots, r_{n}\right)^{\prime}$ and $\boldsymbol{d}=\left[\sum_{i=1}^{n} t_{i j}\right]_{n \times n}^{\prime}=\left(d_{1}, \ldots, d_{j}, \ldots, d_{n}\right)^{\prime}$, respectively. The subscript ' denotes the transpose operation and the operations of $\boldsymbol{r}+\boldsymbol{d}$ and $\boldsymbol{r}-\boldsymbol{d}$ can form two column vectors. When $i=j$, the $i$ th element of $\boldsymbol{r}+\boldsymbol{d}$ (i.e., $r_{i}^{C}+d_{i}^{C}$ ) indicates the relative influence of criterion $i$. Moreover, the operation $\boldsymbol{r}-\boldsymbol{d}$ vector can divide criteria into a cause group and an effect group. If $r_{i}^{C}-d_{i}^{C}>0$, the $i$ th criterion belongs to the cause group; if $r_{i}^{C}-d_{i}^{C}<0$, the effect group. Each cluster (i.e., within a dimension) in the total-influence matrix $T$ can follow the similar approach to calculate $r_{i}^{D}+d_{i}^{D}$ and $r_{i}^{D}-d_{i}^{D}$. The cause-effect analysis can transform the obtained results into an influential network relationship map (INRM), which will be illustrated in Section 3.

The total-influence matrix $\boldsymbol{T}$ obtained from DEMATEL analysis can be normalized to be $\boldsymbol{T}_{C}^{N}$ as Eq. (15); in Eq. (15) $D_{j}$ indicates the $j$ th dimension.

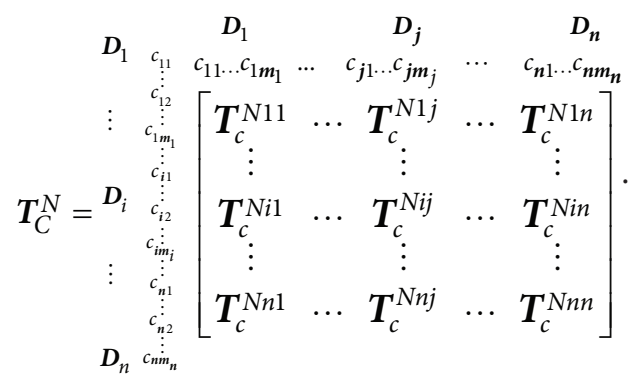

The normalized in Eq. (15) is obtained by the calculation in Eq. (16)-(17). Thus, the total influence matrix can be normalized into an un-weighted super-matrix $W$ in Eq. (18).

$$
d_{i}^{11}=\sum_{j=1}^{m_{1}} t_{C^{i j}}^{11}, i=1,2, \ldots, m_{1}
$$




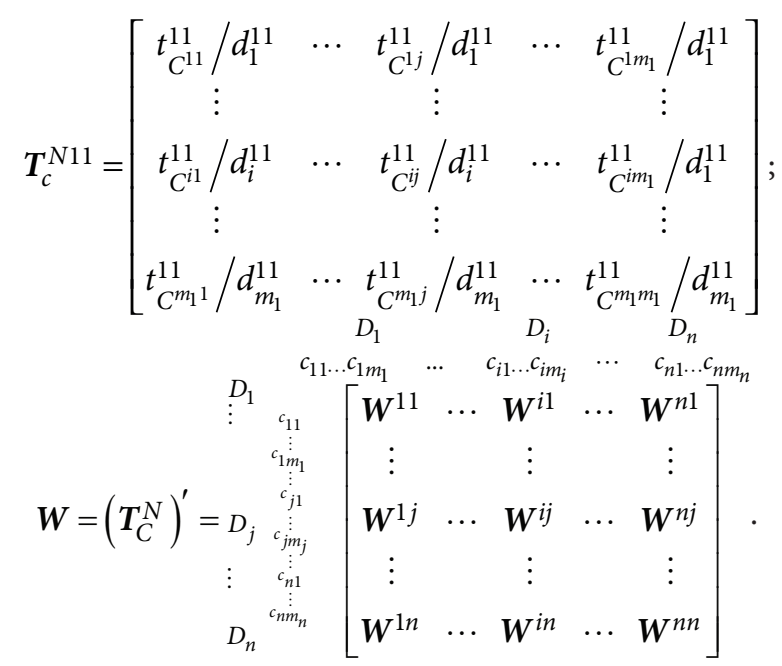

To obtain the weighted super-matrix, the total influence matrix of the dimensions matrix is shown in Eq. (19), which is normalized to be $\boldsymbol{T}_{D}^{N}$ in Eq. (20).

$$
\begin{gathered}
\boldsymbol{T}_{D}=\left[\begin{array}{ccc}
t_{D}^{11} & \ldots & t_{D}^{1 n} \\
\vdots & \ddots & \vdots \\
t_{D}^{n 1} & \cdots & t_{D}^{n n}
\end{array}\right] ; \\
\boldsymbol{T}_{D}^{N}=\left[\begin{array}{ccc}
\frac{t_{D}^{11}}{d_{1}} & \cdots & \frac{t_{D}^{1 n}}{d_{1}} \\
\vdots & \ddots & \vdots \\
\frac{t_{D}^{n 1}}{d_{n}} & \cdots & \frac{t_{D}^{n n}}{d_{n}}
\end{array}\right]=\left[\begin{array}{ccc}
t_{D}^{N 11} & \ldots & t_{D}^{N 1 n} \\
\vdots & \ddots & \vdots \\
t_{D}^{N n 1} & \cdots & t_{D}^{N n n}
\end{array}\right] .
\end{gathered}
$$

The DEMATEL weighted super-matrix $W^{D W}$ can be obtained by multiple $T_{D}^{N}$ with $\boldsymbol{W}$, i.e., $\boldsymbol{W}^{D W}=\boldsymbol{T}_{D}^{N} \boldsymbol{W}$. The weighted super-matrix is multiple by itself multiple times (until stable) to obtain the stable super-matrix. The influential weights of criteria in the DANP can thus be obtained by using the weights for criteria in the limit super-matrix.

Step 8. Based on the DANP weights for each criterion to evaluate (select) improvement plans. The potential (available) improvement plans can be evaluated by domain experts or DMs to get the performance scores on each criterion in the DANP model, and synthesized those performance scores with the influential weights from DANP to get the final score for each potential improvement plan.

The FCA-based DANP model may help a company rank or select improvement plans (proposals) in a quantitative approach, which further extends the applications of MCDM methods in FP decision making. 


\section{Empirical case of semiconductor industry in Taiwan}

The semiconductor industry in Taiwan has formed a strong foundation for the design and production of IT products. Nearly all high influential semiconductor companies are listed in Taiwan's stock market; therefore, this study uses the public-listed semiconductor stocks for examining and illustrating the proposed model. The empirical case comprises of two stages. The first stage is the modeling of FP changes of semiconductor stocks by DRSA method. The second stage illustrates the proposed "identify critical criteria for selecting improvement plans" by using a real stock's financial data in 2012. Furthermore, a sample company was illustrated for identifying its critical performance gap, and five assumed improvement plans were evaluated with the ranking result. The research flow of the illustrated example is as Figure 2.

\subsection{Data}

To capture the FP change patterns, the present study included all of the semiconductor stocks in Taiwan stock market from 2007 to 2012 for DRSA modeling. After excluding incomplete financial data in each year, there were 182 instances (stocks) could be used for training (from 2007 to 2011), and 55 stocks were available to be tested in 2012. The Taiwan stock exchange reports each stock's summary financial result in five aspects with 20 key financial indicators (Table 1), and all of the indicators were adopted as the condition attributes in the DRSA model.

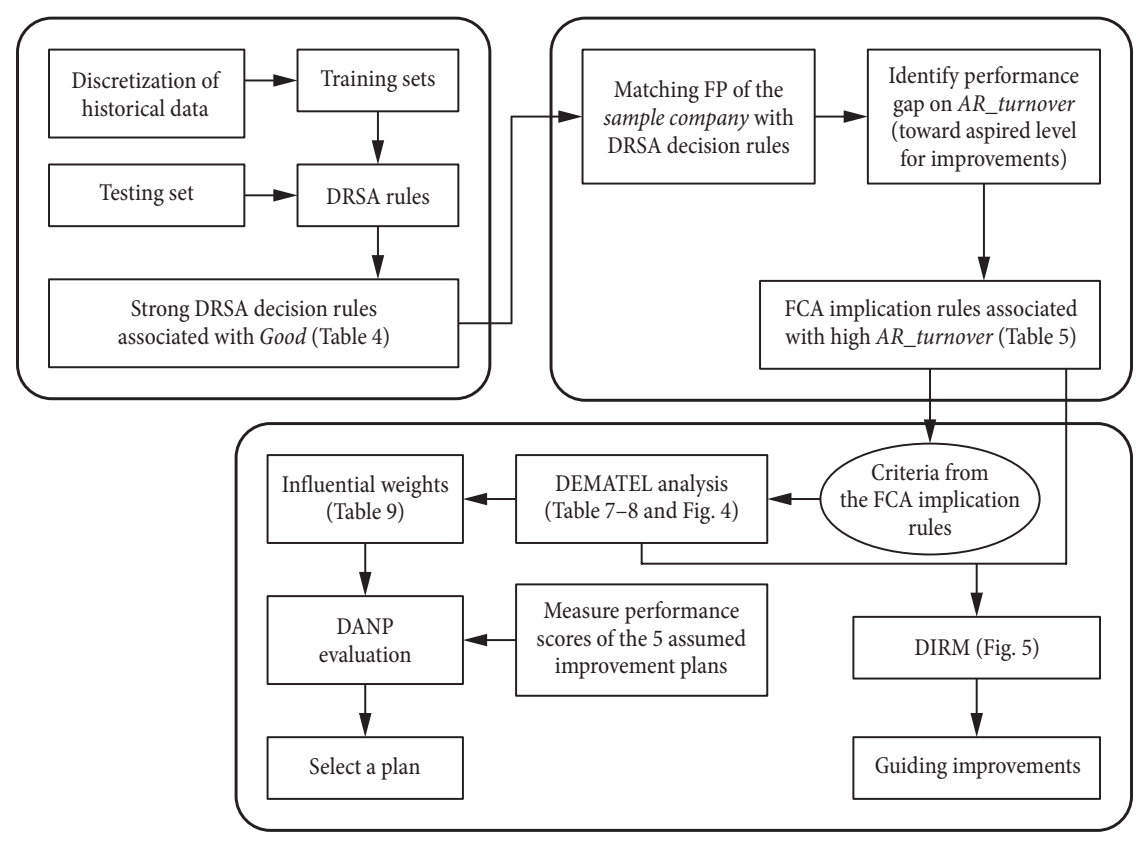

Fig. 2. Illustration of research flows of the empirical case 
Table 1. Definitions of the 20 conditional attributes (financial indicators)

\begin{tabular}{|c|c|c|c|}
\hline Dimensions & Financial ratios & Symbols & Definitions and brief explanations \\
\hline \multirow{2}{*}{$\begin{array}{l}\text { Capital } \\
\text { Structure }\end{array}$} & debt to total asset & Debt & total debt/ total asset \\
\hline & $\begin{array}{l}\text { long-term capital to } \\
\text { total asset }\end{array}$ & LongCapital & long-term capital/total asset \\
\hline \multirow{3}{*}{$\begin{array}{l}\text { Payback } \\
\text { Capability }\end{array}$} & liquidity ratio & Liquidity & current asset/ current liability \\
\hline & speed ratio & Speed & (current asset-inventory)/current liability \\
\hline & $\begin{array}{l}\text { interest coverage } \\
\text { ratio }\end{array}$ & InterestCoverage & $\begin{array}{l}\text { (net profit before tax+interest expense)/ } \\
\text { interest expense }\end{array}$ \\
\hline \multirow[t]{5}{*}{$\begin{array}{l}\text { Operational } \\
\text { Efficiency }\end{array}$} & $\begin{array}{l}\text { accounts receivable } \\
\text { ratio }\end{array}$ & AR_turnover & net credit sales/average accounts receivable \\
\hline & $\begin{array}{l}\text { days for collecting } \\
\text { AR }\end{array}$ & $A R \_$days & $\left(\right.$days $\left.^{\star} \mathrm{AR}\right) /$ credit sales \\
\hline & $\begin{array}{l}\text { inventory turnover } \\
\text { rate }\end{array}$ & InvTurnover & total operational cost/ average inventory \\
\hline & average days for sales & $D A Y s$ & $\begin{array}{l}\text { (average ending inventory/ operational } \\
\text { cost)*365 days }\end{array}$ \\
\hline & $\begin{array}{l}\text { fixed asset turnover } \\
\text { rate }\end{array}$ & FAssetTurnover & total revenue/ total fixed asset \\
\hline \multirow[t]{6}{*}{ Profitability } & return on total asset & $R O A$ & net profit before tax/ average total asset \\
\hline & return on equity & $R O E$ & net profit before tax/ average total equity \\
\hline & $\begin{array}{l}\text { operational profit to } \\
\text { total capital }\end{array}$ & OP_capital & operational profit/total capital \\
\hline & $\begin{array}{l}\text { net profit before tax } \\
\text { to total capital }\end{array}$ & NP_capital & net profit before tax/total capital \\
\hline & net profit ratio & NetProfit & net profit/net sales \\
\hline & earnings per share & EPS & $\begin{array}{l}\text { (net income-dividends on preferred } \\
\text { stocks)/total outstanding shares }\end{array}$ \\
\hline \multirow[t]{3}{*}{ Cash flow } & cash-flow ratio & CashFlow & $\begin{array}{l}\text { (operational cash flow-cash dividend for } \\
\text { preferred stocks)/ weighted average equity }\end{array}$ \\
\hline & $\begin{array}{l}\text { cash-flow adequacy } \\
\text { ratio }\end{array}$ & CashFlow_adq & $\begin{array}{l}\text { cash flow from operation/annual current } \\
\text { maturities }\end{array}$ \\
\hline & $\begin{array}{l}\text { cash-flow } \\
\text { reinvestment ratio }\end{array}$ & CashFlow_inv & $\begin{array}{l}\text { (increase in fixed asset+increase in } \\
\text { working capital)/(net income+noncash } \\
\text { expense-non cash sales-dividends) }\end{array}$ \\
\hline
\end{tabular}

The corresponding ROA changes of each stock in subsequent year were used to denote its decision class; in other words, the DRSA model may be regarded as a one-period lagged model that associates each stock's 20 financial indicators with its own subsequent ROA changes, which is illustrated in Figure 3.

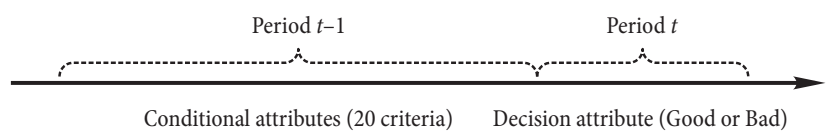

Fig. 3. Time frame of the DRSA model 
The financial data were retrieved from the Taiwan Economic Journal database, and all of the raw financial figures were discretized into three values to indicate "High" (the top 1/3), "Middle" (the middle 1/3), "Low" (the bottom 1/3) as "H", "M", "L" respectively. The adopted three levels discretization ranked all of the available stocks based on the performance of each attribute in each year, and assigned a corresponding value (i.e., " $\mathrm{H}$ " or "M" or "L") for each attribute of a stock; therefore, the discretization supported to identify the relative performance of each stock on the 20 financial attributes in each year. The reasons for adopting the three levels discretization could be summarized in two points: 1) compare the relative performance (on each attribute) in each year to avoid external economic effect; 2) the three discretized values (i.e., "H", "M" and "L") could be denoted as conceptual ideas and analyzed by FCA in the next stage. The decision classes were also discretized in three states according to a stock's corresponding ROA change in the subsequent year (i.e., rank the top $1 / 3$ companies with positive ROA change as Good, the bottom 1/3 companies with negative ROA change as Bad, and the rest as Middle). However, since we aim to explore the patterns that may lead to improvements or deteriorations in the next period, only the stocks categorized as "Good" and "Bad" were kept for rule induction. After excluding stocks that were not categorized as "Good" or "Bad" decision class in each year, there were 145 stocks left as the training set and 35 stocks (in 2012) as the testing set.

\subsection{DRSA model with decision rules}

To construct the DRSA model, a two-step validation was conducted. Since there are only two states for the decision class, we reported the classification accuracy (i.e., correctly classified percentage) instead of mean absolute error (commonly used for ordinal classification problem) in the experiment. In the first step, the training set was examined and compared by four different classifiers: DRSA classifier, support vector machine (SVM), decision tree (DT), and discriminant analysis (DISCRIM). The jMAF software (Błaszczyński et al. 2013) developed by the Laboratory of Intelligent Decision Support Systems was used for DRSA modeling in the study, and the DTREG software for the other three classifiers. A 5-fold cross validation was conducted five times for each classifier, and the average classification accuracy is reported with its standard deviation (SD) in Table 2.

Table 2. Classification accuracy of the training set (unit: \%)

\begin{tabular}{ccccc}
\hline & DRSA & SVM & DT & DISCRIM \\
\hline $1^{\text {st }}$ & 77.93 & 71.73 & 73.50 & 76.55 \\
\hline $2^{\text {nd }}$ & 75.17 & 69.98 & 71.71 & 72.55 \\
\hline $3^{\text {rd }}$ & 76.55 & 71.96 & 68.70 & 70.95 \\
\hline $4^{\text {th }}$ & 78.62 & 68.67 & 59.38 & 74.27 \\
\hline $5^{\text {th }}$ & 77.93 & 70.67 & 74.32 & 71.55 \\
\hline Average & $77.24(1)^{*}$ & $70.60(3)$ & $69.52(4)$ & $73.17(2)$ \\
\hline SD & 1.38 & 1.35 & 6.07 & 2.27 \\
\hline
\end{tabular}

${ }^{*}$ Note: Brackets ( ) denote the ranking results of the average classification accuracy (\%) for the 4 classifiers. 
To examine the performance differences among the four classifiers, a non-parametric Friedman test was conducted, and DRSA classifier was ranked as the top with $\chi^{2}=12.12$ $(\mathrm{df}=3)$, which was significant at the 0.01 confidence level. Therefore, the average of 5 -fold cross validation from DRSA outperformed the other three classifiers. The next step used the whole training set (145 stocks) for DRSA induction, and the testing set (35 stocks) was used to validate the model. The classification accuracy of the training set was $97.24 \%$, and the testing set also generated $85.71 \%$ classification accuracy. The confusion matrix of the testing set is shown as Table 3 (three instances were not able to be classified).

Table 3. Confusion matrix of the testing set

\begin{tabular}{ccc}
\hline & Bad & Good \\
\hline Bad & 16 & 2 \\
\hline Good & 0 & 14 \\
\hline
\end{tabular}

The trained DRSA model generated 24 decision rules with 118 REDUCTs. As this study aims to explore the FP patterns that might lead to improvements in the subsequent period, only the decision rules associated with the at least "Good" decision class (with more than 10 supports) are shown in Table 4.

Table 4. Decision rules associated with at least "Good" decision class

\begin{tabular}{|c|c|}
\hline \multicolumn{2}{|l|}{ Decisions Rules Supports } \\
\hline $\begin{array}{l}\text { If (LongCapital } \geq \mathrm{M} \& \text { Speed } \geq \mathrm{M} \& A R \_ \text {turnover } \geq \mathrm{M} \& A R \_ \text {days } \geq \mathrm{H} \& R O E \geq \mathrm{M} \& \\
\text { CashFlow_adq } \geq \mathrm{M} \text { ) then (DC } \succeq \text { "Good") }\end{array}$ & 17 \\
\hline $\begin{array}{l}\text { If (Speed } \geq \mathrm{M} \& \text { \&R_turnover } \geq \mathrm{H} \& \text { EPS } \geq \mathrm{M} \& \text { CashFlow } \geq \mathrm{H} \& \text { CashFlow_adq } \geq \mathrm{M}) \\
\text { then (DC } \succeq \text { "Good") }\end{array}$ & 16 \\
\hline $\begin{array}{l}\text { If (Debt } \geq \mathrm{M} \& \text { InterestCoverage } \geq \mathrm{M} \& A R \_ \text {turnover } \geq \mathrm{H} \& \text { Inventory } \geq \mathrm{M} \& E P S \geq \mathrm{H} \& \\
\text { CashFlow } \geq \mathrm{M}) \text { then (DC } \succeq \text { "Good") }\end{array}$ & 14 \\
\hline If (LongCapital $\geq \mathrm{M} \& A R \_$days $\geq \mathrm{H} \& R O A \geq \mathrm{M} \&$ CashFlow $\geq \mathrm{H}$ ) then (DC $\succeq$ "Good") & 13 \\
\hline If (AR_Turnover $\geq \mathrm{H}$ \& Inventory $\geq \mathrm{H} \& R O A \geq \mathrm{M} \& E P S \geq \mathrm{M})$ then (DC $\succeq$ "Good") & 12 \\
\hline
\end{tabular}

After obtaining the strong decision rules associated with the at least "Good" decision class, we further illustrate how to construct an evaluation model for a sample stock by the obtained rules. Take the data of semiconductor company Kinsus (code: 3189) in 2012 for example, its financial attributes (LongCapital $=\mathrm{M}$, Speed $=\mathrm{M}, A R \_$turnover $=\mathrm{M}, A R \_$days $=$ $\mathrm{M}, R O E=\mathrm{H}$, CashFlow $=\mathrm{H}$, CashFlow_adq $=\mathrm{H}, E P S=\mathrm{H}$, Debt $=\mathrm{M}$, InterestCoverage $=$ $\mathrm{M}$, Inventory $=\mathrm{M}$ ) meet all of the conditional criteria of the top three decision rules (i.e., Support $=17,16$, and 14) except the attributes $A R \_$turnover (both in the second and third rules of Table 4) and $A R \_$days (in the first rule of Table 4). As the attributes AR_turnover appeared in two of the top three decision rules, the subsequent analysis used it as an example (i.e., the identified performance gap) for improvement planning. 


\subsection{FCA-based DANP method for selecting improvement plans}

To explore the critical attributes that have close relationship with high $A R \_$turnover attribute (notation $A R \_$turnover_H was used to denote $A R \_$turnover with "High" value in FCA implication rules), FCA implication was conducted by analyzing all of the stocks (including the training set and the testing set) categorized as "Good" with high AR_turnover financial attribute. The FCA analysis was done by using the software ConExp, which generated 111 implication rules. The implication rules (covered by more than 10 stocks) associated with high $A R \_$turnover are shown in Table 5.

Table 5. Implication rules associated with high $A R \_$turnover

\begin{tabular}{|c|c|}
\hline Implication rules & Covers \\
\hline $\begin{array}{l}\text { LongCapital_M \& LongCapital_H \& Speed_M \& InterestCoverage_M \& AR_turnover_M \& } \\
\text { Inventory_M \& EPS_M \& CashFlow_adq_M = => AR_turnover_H }\end{array}$ & 12 \\
\hline $\begin{array}{l}\text { Debt_M Debt_H LongCapital_M InterestCoverage_M AR_turnover_M Inventory_M EPS_M } \\
\text { EPS_H CashFlow_adq_M ==>AR_turnover_H }\end{array}$ & 11 \\
\hline $\begin{array}{l}\text { Debt_M Debt_H LongCapital_M InterestCoverage_M AR_turnover_M Inventory_M EPS_M } \\
\text { EPS_H CashFlow_adq_M ==>AR_turnover_H }\end{array}$ & 10 \\
\hline $\begin{array}{l}\text { Debt_M Debt_H LongCapital_M InterestCoverage_M AR_turnover_M Inventory_M ROA_M } \\
\text { EPS_M CashFlow_adq_M ==> AR_turnover_H }\end{array}$ & 10 \\
\hline $\begin{array}{l}\text { Debt_M Debt_H LongCapital_M InterestCoverage_M AR_turnover_M AR_days_H } \\
\text { Inventory_M EPS_M CashFlow_adq_M ==>AR_turnover_H }\end{array}$ & 10 \\
\hline
\end{tabular}

The obtained implication rules in Table 5 indicated that those formal attributes (such as LongCap_M and Speed_M) are the commonly shared attributes for those stocks that were categorized as "Good" decision class with high AR_turnover. In other words, FCA supports to identify the plausible formal attributes that might cause high $A R \_$turnover from the companies in the "Good" decision class. After FCA implication processes, this study used the criteria listed in the top three decision rules (in Table 5) for DANP modeling as an example, and the involved financial criteria were reduced from 20 to seven in Table 6.

The dimensions and criteria listed in Table 6 were adopted for designing the questionnaire for retrieving domain expert's knowledge (experience) regarding FP. In the questionnaire, the asked questions are like: Compare financial attribute $\operatorname{Debt}\left(C_{1}\right)$ to Inventory $\left(C_{5}\right)$, what is the relative influence degree of $C_{1}$ to $C_{5}$ for attaining high $A R \_$trunover (i.e., high

Table 6. Financial attributes that implied high AR_turnover

\begin{tabular}{ll}
\hline \multicolumn{1}{c}{ Dimensions } & \multicolumn{1}{c}{ Criteria (financial attributes) } \\
\hline Capital Structure $\left(D_{1}\right)$ & Debt $\left(C_{1}\right)$ \\
\cline { 2 - 2 } LongCapital $\left(C_{2}\right)$ \\
\hline Payback Capability $\left(D_{2}\right)$ & Speed $\left(C_{3}\right)$ \\
\cline { 2 - 2 } & InterestCoverage $\left(C_{4}\right)$ \\
\hline Operational Efficiency $\left(D_{3}\right)$ & Inventory $\left(C_{5}\right)$ \\
\hline Profitability $\left(D_{4}\right)$ & EPS $\left(C_{6}\right)$ \\
\hline Cash Flow $\left(D_{5}\right)$ & CashFlow_adq $\left(C_{7}\right)$ \\
\hline
\end{tabular}


account receivable turnover)? The answer scale ranges from 0 (no influence) to 4 (extremely high influence). There were eight experts helped to fill the questionnaire, and their all have more than 10 years' working experience in technology sector or financial industry. The experts' job positions include CEO, Vice President, General Manager, Director, CFO, Investment Analyst, Fund Manager, and Senior Manager. The arithmetic mean was calculated for each question (from the eight domain experts), and the raw data collected by questionnaires (for the calculations of DEMATEL and DANP) are in Appendix A; also, the details for obtaining the influential weights of DANP are in Appendix B. The influential network relationship map (INRM) is in Figure 4, and the corresponding relative influential degree (i.e., $r_{i}+d_{i}$ ) and cause-effect group indicator (i.e., $r_{i}-d_{i}$ ) for each dimension and criterion are in Table 7 and Table 8 respectively.

In Figure 4, the inner region denotes the directional influences among the five dimensions, and the outside points or sub-plots denote the directional influences among the criteria (within a dimension). If a dimension has a positive value on $r_{i}^{D}-d_{i}^{D}$, then it implies that this dimension belongs to a cause group.

Table 7. Relative influences of dimensions

\begin{tabular}{lcccc}
\hline \multicolumn{1}{c}{ Dimensions } & $r_{i}^{D}$ & $d_{i}^{D}$ & $r_{i}^{D}+d_{i}^{D}$ & $r_{i}^{D}-d_{i}^{D}$ \\
\hline Capital Structure $\left(D_{1}\right)$ & 4.281 & 4.286 & 8.567 & -0.005 \\
\hline Payback Capability $\left(D_{2}\right)$ & 4.069 & 4.271 & 8.340 & -0.202 \\
\hline Operational Efficiency $\left(D_{3}\right)$ & 4.208 & 3.699 & 7.907 & 0.510 \\
\hline Profitability $\left(D_{4}\right)$ & 4.024 & 4.737 & 8.761 & -0.713 \\
\hline Cash Flow $\left(D_{5}\right)$ & 4.113 & 3.702 & 7.815 & 0.411 \\
\hline
\end{tabular}

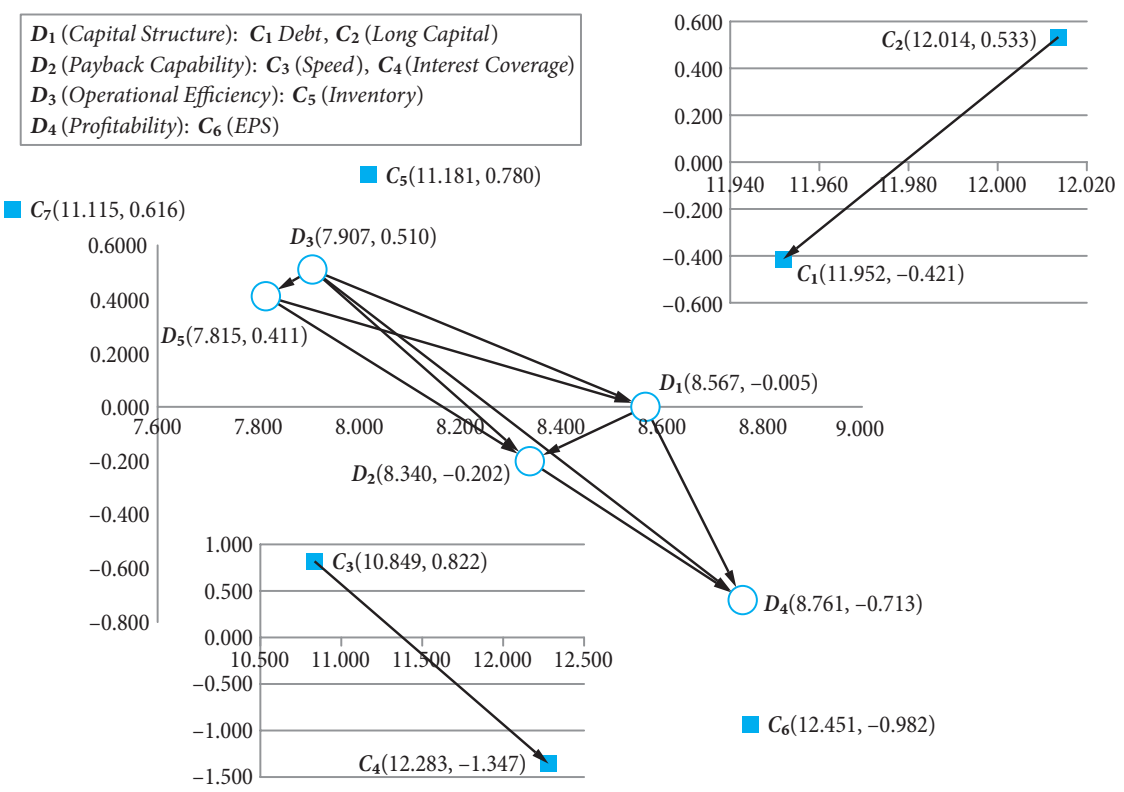

Fig. 4. Influential network relationship map (INRM) 
Table 8. Relative influences of criteria

\begin{tabular}{lcccc}
\hline \multicolumn{1}{c}{ Criteria } & $r_{i}^{C}$ & $d_{i}^{C}$ & $r_{i}^{C}+d_{i}^{C}$ & $r_{i}^{C}-d_{i}^{C}$ \\
\hline Debt $\left(C_{1}\right)$ & 5.765 & 6.187 & 11.952 & -0.421 \\
\hline LongCapital $\left(C_{2}\right)$ & 6.274 & 5.740 & 12.014 & 0.533 \\
\hline Speed $\left(C_{3}\right)$ & 5.835 & 5.014 & 10.849 & 0.822 \\
\hline InterestCoverage $\left(C_{4}\right)$ & 5.468 & 6.815 & 12.283 & -1.347 \\
\hline Inventory $\left(C_{5}\right)$ & 5.981 & 5.200 & 11.181 & 0.780 \\
\hline EPS $\left(C_{6}\right)$ & 5.734 & 6.717 & 12.451 & -0.982 \\
\hline CashFlow_adq $\left(C_{7}\right)$ & 5.866 & 5.250 & 11.115 & 0.616 \\
\hline
\end{tabular}

\section{Result of the improvement plan selection and discussions}

To illustrate how to apply the obtained weights (from FCA-based DANP model) to select improvement plans, the assumed five improvement plans (i.e., $A, B, C, D$, and $E$ plans) with the weights for each criterion are in Table 9. From logical perspective, the implication rules that associated with high $A R \_$turnover contain the granule of concepts that might cause high $A R \_$turnover. Thus, the constructed DANP evaluation model comprises of those granule of concepts (i.e., criteria) for attaining high AR_turnover, which could be applied to select improvement plans. The assumed performance scores of each plan on each criterion may be obtained by internal management team to rank the relative performance that each improvement plan might have for attaining high $A R \_$turnover. In this example (in Table 9), a five-point Likert scale is assumed for illustration.

As indicated in Table 9, the summed score of plan $D$ is 1.643 , which supposed to be the best choice by the proposed model. According to the FCA-based DANP model, the company Kinsus should select plan $D$ to improve its $A R \_$turnover result. Furthermore, by the results in Table 5 (implication rules from FCA), Table 7, Table 9, and Figure 4 (INRM), the proposed model further explored the directional influences among the dimensions and criteria that imply high $A R \_$turnover. The integration of the implication rules and INRM

Table 9. The influential weights of DANP and the assumed performance scores of the five plans

\begin{tabular}{lcccccc}
\hline \multirow{2}{*}{ Criteria } & Influential & \multicolumn{5}{c}{ Performance score ${ }^{*}$ on each criterion } \\
\cline { 3 - 7 } weights & $\mathrm{A}$ & $\mathrm{B}$ & $\mathrm{C}$ & $\mathrm{D}$ & $\mathrm{E}$ \\
\hline Debt $\left(C_{1}\right)$ & 0.107 & 3 & 5 & 1 & 2 & 4 \\
\hline LongCapital $\left(\mathrm{C}_{2}\right)$ & 0.100 & 2 & 3 & 4 & 1 & 5 \\
\hline Speed $\left(C_{3}\right)$ & 0.088 & 5 & 3 & 2 & 1 & 4 \\
\hline InterestCoverage $\left(C_{4}\right)$ & 0.118 & 3 & 2 & 4 & 1 & 5 \\
\hline Inventory $\left(C_{5}\right)$ & 0.179 & 2 & 3 & 1 & 4 & 5 \\
\hline EPS $\left(C_{6}\right)$ & 0.228 & 3 & 4 & 2 & 1 & 5 \\
\hline CashFlow_Adq $\left(C_{7}\right)$ & 0.179 & 4 & 2 & 3 & 1 & 5 \\
\hline Summed scores Ranks & & $3.073(3)$ & $3.142(4)$ & $2.327(2)$ & $1.643(1)$ & $4.800(5)$ \\
\hline
\end{tabular}

Note: ${ }^{*}$ A five-point Likert scale $(1,2,3,4,5)$ is assumed with ascending order (i.e., 1 is better than 5$)$. 


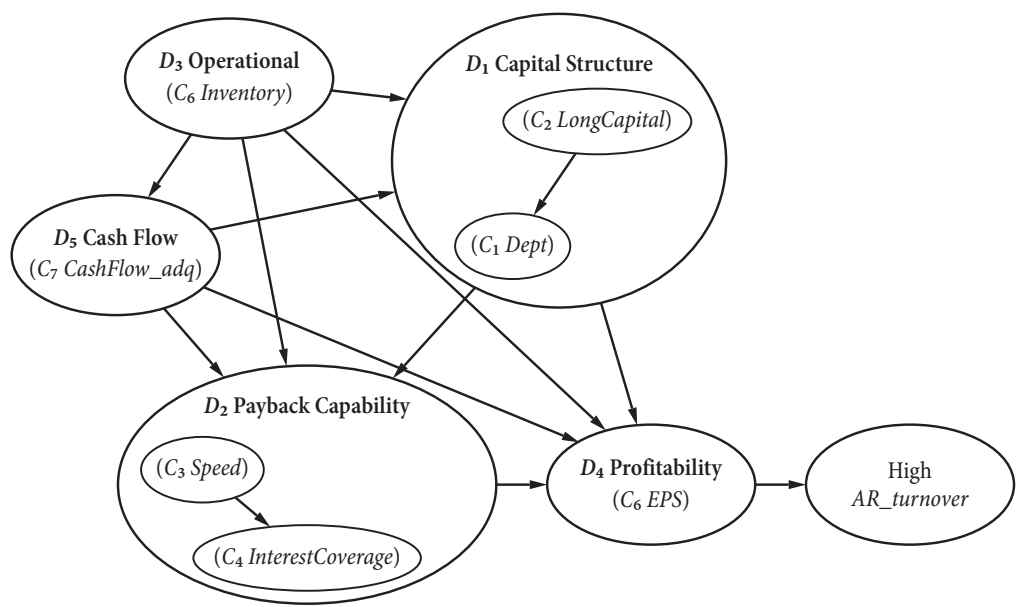

Fig. 5. Directional implication relationship map (DIRM)

may provide more managerial insights regarding the FP pattern changes, illustrated and termed as directional implication relationship map (DIRM) in Figure 5.

The obtained DIRM not only indicated the directional influences among the five dimensions, but also incorporated with implication rules to provide more insights. First, as indicated in Figure 5, to reach high $A R \_$turnover, the source dimension should be Operational $\left(D_{3}\right)$, and $D_{3}$ have influences on the other four dimensions (i.e., $D_{1}, D_{2}, D_{4}$, and $D_{5}$ ). Therefore, the criterion Inventory $\left(C_{5}\right)$ in dimension $D_{3}$ should be considered as the top priority while planning for an improvement plan. Second, refer to DANP weights for each criterion in Table 9, the top three influential criteria are $C_{6}(0.228), C_{5}(0.179)$, and $C_{7}(0.179)$ respectively. However, the criterion EPS $\left(C_{6}\right)$ belongs to the effect group $\left(r_{i}^{C}-d_{i}^{C}=-0.982<0\right)$, which should be influenced by the other dimensions and criteria. Therefore, Inventory $\left(C_{5}\right)$ and CashFlow_adq $\left(C_{7}\right)$ should be considered as the most critical criteria to enhance its performance, which might cause relatively higher marginal effects for attaining high $A R \_$turnover. Third, dimensions $D_{1}, D_{2}$, and $D_{5}$ all have influences on dimension $D_{4}$ (Profitability), the management team of Kinsus may examine its current performances on the three dimensions and related criteria (i.e., $C_{1}, C_{2}, C_{3}, C_{4}$, and $C_{7}$ ), to see if there was any underperformed criterion that should be addressed. The aforementioned insights could not be provided by conventional regression models, which are also the novelty and main contributions of the proposed approach.

\section{Conclusions and remarks}

To conclude, the present study proposes a combined model by integrating computational intelligence (i.e., DRSA) and MCDM methods (i.e., DEMATEL and DANP) to diagnose FP of semiconductor companies. Compared with previous studies (Hsu et al. 2012, 2013; Ou Yang et al. 2013; Shen et al. 2014) that constructed MCDM evaluation models by interviews or literature review to select the involved criteria/dimensions, the proposed 
model - conducted by logical reasoning from historical data - is based on the implication rules of FCA. Compared with the REDUCTs (describe each minimal subset of criteria that may deliver the same quality of approximation to classify "Good" and "Bad" decision classes) from DRSA, the obtained critical attributes only analyzed those "Good" alternatives. The purpose is to retrieve the other commonly shared attributes based on the fact that those "Good" alternatives have the same formal concept "AR_turnover_H (i.e., high AR_turnover)", which is the target for the sample company to reach (improve). As a result, the DANP model at the second stage would have a reasonable foundation, which is also the critical point to transform the findings of DRSA into a hybrid MCDM model. Furthermore, the obtained figurative results (i.e., INRM and DIRM) may help DMs to gain more understandable insights (cause-effect influences in implication rules) compared with a single approach (computational approach or MCDM approach), which are the novel applications and major contributions in this study. The results indicate that the integrated model may resolve the FP diagnosis problem, and evaluate future improvement plans in a reasonable manner.

Our findings provide an integrated approach to resolve complex financial problems in real business environment. Nevertheless, there are still several limitations in the present study. First, the used DRSA model was based on the assumption: historical financial patterns will reoccur in the near future, and the model was based on the data in recent five years to form patterns and decision rules. Second, the adopted three-level discretization method in DRSA might generate different results by using the other discretization methods. More discretization methods are suggested to be examined to explore its effects on DRSA model in the future. Third, though the real semiconductor companies' data were applied in the empirical case, the selection of improvement plans was illustrated by assumed plans; the present research may be regarded as a pilot study. By jointly-working with a company, future studies are suggested to evaluate real improvement plans based on the proposed method. Finally, this study only uses the DRSA decision rules associated with the "at least Good" decision class to highlight the FP patterns for improvements; future studies may examine the rules associated with the "at most Bad" decision class to explore the FP patterns and construct a corresponding evaluation model - to avoid performance deteriorations.

\section{References}

Ahn, B. S.; Cho, S. S.; Kim, C. Y. 2000. The integrated methodology of rough set theory and artificial neural network for business failure prediction, Expert Systems with Applications 18(2): 65-74. http://dx.doi.org/10.1016/S0957-4174(99)00053-6

Aydogan, E. K. 2011. Performance measurement model for Turkish aviation firms using the rough-AHP and TOPSIS methods under fuzzy environment, Expert Systems with Applications 38(4): 3992-3998. http://dx.doi.org/10.1016/j.eswa.2010.09.060

Bahrammirzaee, A. 2010. A comparative survey of artificial intelligence applications in finance: artificial neural networks, expert system and hybrid intelligent systems, Neural Computing and Applications 19(8): 1165-1195. http://dx.doi.org/10.1007/s00521-010-0362-z

Beynon, M. J.; Peel, M. J. 2001. Variable precision rough set theory and data discretisation: an application to corporate failure prediction, Omega 29(6): 561-576.

http://dx.doi.org/10.1016/S0305-0483(01)00045-7 
Błaszczyński. J.; Greco, S.; Matarazzo, B.; Słowiński, R.; Szelag, M. 2013. jMAF-Dominance-based rough set data analysis framework, in Rough Sets and Intelligent Systems-Professor Zdzisław Pawlak in Memoriam. Springer, 185-209.

Błaszczyński, J.; Greco, S.; Słowiński, R. 2007. Multi-criteria classification - a new scheme for application of dominance-based decision rules, European Journal of Operational Research 181(3): 1030-1044. http://dx.doi.org/10.1016/j.ejor.2006.03.004

Boyacioglu, M. A.; Avci, D. 2010. An adaptive network-based fuzzy inference system (ANFIS) for the prediction of stock market return: the case of the Istanbul stock exchange, Expert Systems with Applications 37(12): 7908-7912. http://dx.doi.org/10.1016/j.eswa.2010.04.045

Ergul, N.; Oktem, R. 2011. Searching of usability of TOPSIS and ELECTRE methods in measurement and evaluation of financial performance of construction and public works companies, Applied Finance 2(9): 1086-1100.

Diakoulaki, D.; Mavrotas, G.; Papayannakis, L. 1992. A multicriteria approach for evaluating the performance of industrial firms, Omega 20(4): 467-474. http://dx.doi.org/10.1016/0305-0483(92)90021-X

Dimitras, A. I.; Slowinski, R.; Susmaga, R.; Zopounidis, C. 1999. Business failure prediction using rough sets, European Journal of Operational Research 114(2): 263-280. http://dx.doi.org/10.1016/S0377-2217(98)00255-0

Fang, S. K.; Shyng, J. Y.; Lee, W. S.; Tzeng, G. H. 2012. Exploring the preference of customers between financial companies and agents based on TCA, Knowledge-Based Systems 27: 137-151. http://dx.doi.org/10.1016/j.knosys.2011.09.003

Gabus, A.; Fontela, E. 1972. World problems, an invitation to further thought within the framework of DEMATEL. Battelle Geneva Research Center, Geneva, Switzerland.

Ganter, B.; Wille, R.; Franzke, C. 1997. Formal concept analysis: mathematical foundations. New York: Springer-Verlag, Inc.

Greco, S.; Matarazzo, B.; Pappalardo, N.; Slowinski, R. 2005. Measuring expected effects of interventions based on decision rules, Journal of Experimental \& Theoretical Artificial Intelligence 17(1-2): 103-118. http://dx.doi.org/10.1080/09528130512331315864

Greco, S.; Matarazzo, B.; Slowinski, R. 2002. Multicriteria classification by dominance-based rough set approach, Handbook of data mining and knowledge discovery. New York: Oxford University Press.

Greco, S.; Slowinski, R.; Stefanowski, J. 2001. Variable consistency model of dominance-based rough sets approach, in Rough Sets and Current Trends in Computing. Springer, 170-181. http://dx.doi.org/10.1007/3-540-45554-X_20

Hsu, C. C.; Liou, J. J.; Chuang, Y. C. 2013. Integrating DANP and modified grey relation theory for the selection of an outsourcing provider, Expert Systems With Applications 40(6): 2297-2304. http://dx.doi.org/10.1016/j.eswa.2012.10.040

Hsu, C. H.; Wang, F. K.; Tzeng, G. H. 2012. The best vendor selection for conducting the recycled material based on a hybrid MCDM model combining DANP with VIKOR, Resources, Conservation and Recycling 66: 95-111. http://dx.doi.org/10.1016/j.resconrec.2012.02.009

Hu, S. K.; Chuang, Y. C.; Yeh, Y. F.; Tzeng, G. H. 2012. Combining hybrid MADM with fuzzy integral for exploring the smart phone improvement in M-Generation, International Journal of Fuzzy Systems 14(2): 204-214.

Hu, S. K.; Lu, M. T.; Tzeng, G. H. 2014. Exploring smart phone improvements based on a hybrid MCDM model, Expert Systems with Applications 41(9): 4401-4413.

http://dx.doi.org/10.1016/j.eswa.2013.12.052

Jassbi, J.; Mohamadnejad, F.; Nasrollahzadeh, H. 2011. A Fuzzy DEMATEL framework for modeling cause and effect relationships of strategy map, Expert systems with Applications 38(5): 5967-5973. http://dx.doi.org/10.1016/j.eswa.2010.11.026 
Lam, M. 2004. Neural network techniques for financial performance prediction: integrating fundamental and technical analysis, Decision Support Systems 37(4): 567-581. http://dx.doi.org/10.1016/S0167-9236(03)00088-5

Lin, Y. T.; Yang, Y. H.; Kang, J. S.; Yu, H. C. 2011. Using DEMATEL method to explore the core competences and causal effect of the IC design service company: an empirical case study, Expert Systems with Applications 38(5): 6262-6268. http://dx.doi.org/10.1016/j.eswa.2010.11.092

Liou, J. J.; Tzeng, G. H. 2010. A dominance-based rough set approach to customer behavior in the airline market, Information Sciences 180(11): 2230-2238. http://dx.doi.org/10.1016/j.ins.2010.01.025

Liou, J. J.; Tzeng, G. H. 2012. Comments on "Multiple criteria decision making (MCDM) methods in economics: an overview", Technological and Economic Development of Economy 18(4): 672-695. http://dx.doi.org/10.3846/20294913.2012.753489

Liou, J. J. 2013. New concepts and trends of MCDM for tomorrow - in honor of Professor GwoHshiung Tzeng on the occasion of his $70^{\text {th }}$ birthday, Technological and Economic Development of Economy 19(2): 367-375. http://dx.doi.org/10.3846/20294913.2013.811037

Mareschal, B.; Brans, J. P. 1991. BANKADVISER: an industrial evaluation system, European Journal of Operational Research 54(3): 318-324. http://dx.doi.org/10.1016/0377-2217(91)90106-6

Mareschal, B.; Mertens, D. 1992. BANKS a multicriteria, PROMETHEE-based, decision support system for the evaluation of the international banking sector, Journal of Decision Systems 1(2-3): 175-189. http://dx.doi.org/10.1080/12460125.1992.10511524

Opricovic, S.; Tzeng, G. H. 2004. Compromise solution by MCDM methods: a comparative analysis of VIKOR and TOPSIS, European Journal of Operational Research 156(2): 445-455. http://dx.doi.org/10.1016/S0377-2217(03)00020-1

Ou Yang, Y. P.; Shieh, H. M.; Leu, J. D.; Tzeng, G. H. 2008. A novel hybrid MCDM model combined with DEMATEL and ANP with applications, International Journal of Operations Research 5(3): 160-168.

Ou Yang, Y. P.; Shieh, H. M.; Tzeng, G. H.; Yen, L.; Chan, C. C. 2011. Combined rough sets with flow graph and formal concept analysis for business aviation decision-making, Journal of Intelligent Information Systems 36(3): 347-366. http://dx.doi.org/10.1007/s10844-009-0110-y

Ou Yang, Y. P.; Shieh, H. M.; Tzeng, G. H. 2013. A VIKOR technique based on DEMATEL and ANP for information security risk control assessment, Information Sciences 232: 482-500. http://dx.doi.org/10.1016/j.ins.2011.09.012

Pawlak, Z. 1982. Rough sets, International Journal of Computer \& Information Sciences 11(5): 341-356. http://dx.doi.org/10.1007/BF01001956

Penman, S. H. 2007. Financial statement analysis and security valuation. New York, NY: McGraw-Hill/ Irwin.

Peng, K. H.; Tzeng, G. H. 2013. A hybrid dynamic MADM model for problems-improvement in economics and business, Technological and Economic Development of Economy 19(4): 638-660. http://dx.doi.10.1080/03081068908717407

Piotroski, J. D. 2000. Value investing: the use of historical financial statement information to separate winners from losers, Journal of Accounting Research 38: 1-52. http://dx.doi.org/10.2307/2672906

Ravi, V.; Kurniawan, H.; Thai, P. N. K.; Kumar, P. R. 2008. Soft computing system for bank performance prediction, Applied Soft Computing 8(1): 305-315. http://dx.doi.org/10.1016/j.asoc.2007.02.001

Saaty, T. L. 1988. What is the analytic hierarchy process? Springer.

Saaty, T. L. 2004. Decision making - the analytic hierarchy and network processes (AHP/ANP), Journal of Systems Science and Systems Engineering 13(1): 1-35. http://dx.doi.org/10.1007/s11518-006-0151-5 
Shen, K. Y. 2011. Implementing value investing strategy by artificial neural network, International Journal of Business and Information Technology 1(1): 12-22.

Shen, K. Y.; Yan, M. R.; Tzeng, G. H. 2014. Combining VIKOR-DANP model for glamor stock selection and stock performance improvement, Knowledge-Based Systems 58: 86-97. http://dx.doi.org/10.1016/j.knosys.2013.07.023

Shen, K. Y.; Tzeng, G. H. 2015. A decision rule-based soft computing model for diagnosing financial performance improvement of commercial banks, Soft Computing 19(4): 859-874. http://dx.doi.org/10.1007/s00500-014-1413-7

Shen, K. Y.; Tzeng, G. H. 2014. DRSA-based neuro-fuzzy inference systems for the financial performance prediction of commercial bank, International Journal of Fuzzy Systems 16(2): 173-183.

Shuai, J. J.; Li, H. L. 2005. Using rough set and worst practice DEA in business failure prediction, in Rough Sets, Fuzzy Sets, Data Mining, and Granular Computing (LNCS series), Chapter 53. Springer, 503-510. http://dx.doi.org/10.1007/11548706_53

Shyng, J. Y.; Shieh, H. M.; Tzeng, G. H. 2010a. An integration method combining rough set theory with formal concept analysis for personal investment portfolios, Knowledge-Based Systems 23(6): 586-597. http://dx.doi.org/10.1016/j.knosys.2010.04.003

Shyng, J. Y.; Shieh, H. M.; Tzeng, G. H.; Hsieh, S. H. 2010b. Using FSBT technique with rough set theory for personal investment portfolio analysis, European Journal of Operational Research 201(2): 601-607. http://dx.doi.org/10.1016/j.ejor.2009.03.031

Spronk, J.; Steuer, R. E.; Zopounidis, C. 2005. Multicriteria decision aid/analysis in finance, in Multiple criteria decision analysis: State of the art surveys. Springer, 799-848.

Steuer, R. E.; Na, P. 2003. Multiple criteria decision making combined with finance: a categorized bibliographic study, European Journal of Operational Research 150(3): 496-515. http://dx.doi.org/10.1016/S0377-2217(02)00774-9

Tay, E. H.; Shen, L. 2002. Economic and financial prediction using rough sets model, European Journal of Operational Research 141(3): 641-659. http://dx.doi.org/10.1016/S0377-2217(01)00259-4

Tilley, T.; Cole, R.; Becker, P.; Eklund, P. 2005. A survey of formal concept analysis support for software engineering activities, in Formal concept analysis. Springer, 250-271. http://dx.doi.org/10.1007/11528784_13

Tseng, M. L. 2009. A causal and effect decision making model of service quality expectation using greyfuzzy DEMATEL approach, Expert Systems with Applications 36(4): 7738-7748. http://dx.doi.org/10.1016/j.eswa.2008.09.011

Tsui, C. W.; Tzeng, G. H.; Wen, U. P. 2014. A hybrid MCDM approach for improving the performance of green suppliers in the TFT-LCD industry, International Journal of Production Research (in press). http://dx.doi.10.1080/00207543.2014.935829

Tzeng, G. H.; Shieh, H. M.; Shian, T. A. 1989. Route choice behavior in transportation and application of the multiattribute utility theorem, Transportation Planning and Technology (An International Journal) 13(4): 289-301. http://dx.doi.10.1080/03081068908717407

Wang, J. L.; Chan, S. H. 2006. Stock market trading rule discovery using two-layer bias decision tree, Expert Systems with Applications 30(4): 605-611. http://dx.doi.org/10.1016/j.eswa.2005.07.006

Wille, R. 2005. Formal concept analysis as mathematical theory of concepts and concept hierarchies, in Formal concept analysis. Springer, 1-33. http://dx.doi.org/10.1007/11528784_1

Xidonas, P.; Mavrotas, G.; Psarras, J. 2009. A multicriteria methodology for equity selection using financial analysis, Computers \& Operations Research 36(12): 3187-3203. http://dx.doi.org/10.1016/j.cor.2009.02.009

Yang, J. L.; Tzeng, G. H. 2011. An integrated MCDM technique combined with DEMATEL for a novel cluster-weighted with ANP method, Expert Systems with Applications 38(3): 1417-1424. http://dx.doi.org/10.1016/j.eswa.2010.07.048 
Yeh, C. H.; Deng, H.; Chang, Y. H. 2000. Fuzzy multicriteria analysis for performance evaluation of bus companies, European Journal of Operational Research 126(3): 459-473.

http://dx.doi.org/10.1016/S0377-2217(99)00315-X

Zaras, K. 2011. The Dominance-based Rough Set Approach (DRSA) applied to bankrupcy prediction modeling for small and medium businesses, in Multiple Criteria Decision Making. The University of Economics in Katowice, 287-295.

Zopounidis, C.; Doumpos, M. 2013. Multicriteria decision systems for financial problems, Top 21(2): 241-261. http://dx.doi.org/10.1007/s11750-013-0279-7

Zopounidis, C.; Godefroid, M.; Hurson, C. 1995. Designing a multicriteria decision support system for portfolio selection and management, in Advances in stochastic modelling and data analysis. Springer, 261-292. http://dx.doi.org/10.1007/978-94-017-0663-6_17

\section{APPENDIX A}

\section{(Raw data for the calculations of DEMATEL and DANP)}

Table A1. Raw data from eight domain experts

\begin{tabular}{|c|c|c|c|c|c|c|c|c|c|c|}
\hline \multirow{2}{*}{$\begin{array}{c}\mathrm{C} i-j \\
\text { Criterion } \\
i \text { to } j \text { ) }\end{array}$} & \multicolumn{8}{|c|}{ Respondent (domain expert) } & \multirow{2}{*}{$\begin{array}{c}\text { average } \\
\text { (8 experts) }\end{array}$} & \multirow{2}{*}{$\begin{array}{c}\text { average } \\
\text { (7 experts) }\end{array}$} \\
\hline & 1 & 2 & 3 & 4 & 5 & 6 & 7 & 8 & & \\
\hline $\mathrm{C} 1-2$ & 4 & 3 & 4 & 3 & 4 & 4 & 3 & 4 & 3.63 & 3.57 \\
\hline $\mathrm{C} 1-3$ & 1 & 1 & 1 & 2 & 1 & 1 & 2 & 1 & 1.25 & 1.29 \\
\hline $\mathrm{C} 1-4$ & 4 & 3 & 4 & 3 & 4 & 2 & 4 & 2 & 3.25 & 3.43 \\
\hline $\mathrm{C} 1-5$ & 1 & 2 & 1 & 2 & 3 & 1 & 3 & 1 & 1.75 & 1.86 \\
\hline $\mathrm{C} 1-6$ & 3 & 2 & 3 & 3 & 2 & 3 & 2 & 3 & 2.63 & 2.57 \\
\hline $\mathrm{C} 1-7$ & 1 & 2 & 1 & 1 & 1 & 1 & 2 & 1 & 1.25 & 1.29 \\
\hline C2-1 & 4 & 3 & 4 & 4 & 3 & 2 & 4 & 2 & 3.25 & 3.43 \\
\hline $\mathrm{C} 2-3$ & 1 & 1 & 1 & 1 & 2 & 1 & 2 & 1 & 1.25 & 1.29 \\
\hline C2-4 & 3 & 3 & 3 & 4 & 4 & 3 & 4 & 4 & 3.50 & 3.43 \\
\hline C2-5 & 1 & 1 & 1 & 1 & 3 & 1 & 1 & 2 & 1.38 & 1.29 \\
\hline C2-6 & 3 & 2 & 3 & 3 & 2 & 3 & 3 & 3 & 2.75 & 2.71 \\
\hline C2-7 & 4 & 2 & 4 & 4 & 2 & 3 & 4 & 2 & 3.13 & 3.29 \\
\hline C3-1 & 1 & 1 & 2 & 2 & 1 & 3 & 1 & 1 & 1.50 & 1.57 \\
\hline C3-2 & 1 & 1 & 2 & 1 & 1 & 2 & 1 & 1 & 1.25 & 1.29 \\
\hline C3-4 & 2 & 2 & 3 & 4 & 2 & 1 & 3 & 1 & 2.25 & 2.43 \\
\hline C3-5 & 4 & 3 & 4 & 4 & 2 & 4 & 3 & 2 & 3.25 & 3.43 \\
\hline C3-6 & 3 & 3 & 2 & 4 & 3 & 4 & 3 & 2 & 3.00 & 3.14 \\
\hline C3-7 & 3 & 2 & 3 & 3 & 2 & 4 & 3 & 2 & 2.75 & 2.86 \\
\hline C4-1 & 3 & 2 & 3 & 1 & 3 & 4 & 3 & 1 & 2.50 & 2.71 \\
\hline C4-2 & 2 & 2 & 3 & 2 & 1 & 2 & 3 & 2 & 2.13 & 2.14 \\
\hline C4-3 & 1 & 1 & 1 & 1 & 2 & 1 & 3 & 1 & 1.38 & 1.43 \\
\hline C4-5 & 1 & 2 & 1 & 1 & 3 & 1 & 2 & 1 & 1.50 & 1.57 \\
\hline C4-6 & 4 & 4 & 4 & 3 & 4 & 3 & 4 & 2 & 3.50 & 3.71 \\
\hline
\end{tabular}


End of Table A1

\begin{tabular}{|c|c|c|c|c|c|c|c|c|c|c|}
\hline \multirow{2}{*}{ 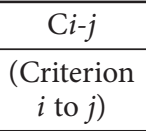 } & \multicolumn{8}{|c|}{ Respondent (domain expert) } & \multirow{2}{*}{$\begin{array}{c}\text { average } \\
\text { (8 experts) }\end{array}$} & \multirow{2}{*}{$\begin{array}{c}\text { average } \\
\text { ( } 7 \text { experts) }\end{array}$} \\
\hline & 1 & 2 & 3 & 4 & 5 & 6 & 7 & 8 & & \\
\hline $\mathrm{C} 4-7$ & 2 & 2 & 1 & 3 & 2 & 1 & 3 & 2 & 2.00 & 2.00 \\
\hline C5-1 & 2 & 2 & 1 & 3 & 3 & 2 & 3 & 2 & 2.25 & 2.29 \\
\hline C5-2 & 2 & 2 & 2 & 2 & 1 & 2 & 3 & 2 & 2.00 & 2.00 \\
\hline C5-3 & 4 & 4 & 4 & 3 & 4 & 3 & 4 & 2 & 3.50 & 3.71 \\
\hline C5-4 & 2 & 2 & 3 & 2 & 1 & 2 & 3 & 2 & 2.13 & 2.14 \\
\hline C5-6 & 3 & 3 & 4 & 2 & 3 & 4 & 3 & 2 & 3.00 & 3.14 \\
\hline C5-7 & 2 & 2 & 1 & 2 & 1 & 1 & 2 & 1 & 1.50 & 1.57 \\
\hline C6-1 & 2 & 3 & 3 & 2 & 2 & 2 & 1 & 3 & 2.25 & 2.14 \\
\hline C6-2 & 2 & 2 & 3 & 3 & 2 & 3 & 2 & 1 & 2.25 & 2.43 \\
\hline C6-3 & 2 & 1 & 2 & 2 & 1 & 3 & 2 & 1 & 1.75 & 1.86 \\
\hline C6-4 & 4 & 4 & 4 & 4 & 3 & 4 & 3 & 2 & 3.50 & 3.71 \\
\hline C6-5 & 2 & 2 & 3 & 2 & 1 & 2 & 3 & 2 & 2.13 & 2.14 \\
\hline C6-7 & 2 & 2 & 2 & 2 & 2 & 1 & 3 & 1 & 1.88 & 2.00 \\
\hline C7-1 & 3 & 3 & 3 & 4 & 3 & 4 & 3 & 2 & 3.13 & 3.29 \\
\hline C7-2 & 2 & 2 & 3 & 1 & 2 & 3 & 2 & 3 & 2.25 & 2.14 \\
\hline C7-3 & 4 & 2 & 4 & 3 & 2 & 3 & 4 & 2 & 3.00 & 3.14 \\
\hline C7-4 & 2 & 2 & 1 & 3 & 2 & 1 & 2 & 1 & 1.75 & 1.86 \\
\hline C7-5 & 3 & 3 & 2 & 4 & 2 & 2 & 3 & 1 & 2.50 & 2.71 \\
\hline C7-6 & 2 & 1 & 1 & 2 & 1 & 1 & 2 & 1 & 1.38 & 1.43 \\
\hline
\end{tabular}

Note: $\frac{1}{n(n-1)} \sum_{i=1}^{n} \sum_{j=1}^{n} \frac{\left|a_{i j}^{p}-a_{i j}^{p-1}\right|}{a_{i j}^{p}} \times 100 \%=3.24 \%<5 \%$, where $a_{i j}^{p}$ and $a_{i j}^{p-1}$ denote the average influence of criterion $i$ on criterion $j$ by experts $p$ and $p$-1, respectively; $n$ denotes the number of criteria $(n=7$ and $p=8$ in here).

Thus, the results above are confidence of significance at the $96.76 \%$ level, which is greater than $95 \%$ level. 


\section{APPENDIX B}

\section{(Detail calculations of DANP)}

Refer to Step 6 and Step 7 in Subsection 2.3 and Eq. (10) - Eq. (20) for obtaining Table B1 to Table B8.

Table B1. Initial influence matrix $\boldsymbol{A}$

\begin{tabular}{ccccccccc}
\hline Criteria & $C_{1}$ & $C_{2}$ & $C_{3}$ & $C_{4}$ & $C_{5}$ & $\mathrm{C}_{6}$ & $C_{7}$ & sum \\
\hline$C_{1}$ & 0.000 & 3.625 & 1.250 & 3.250 & 1.750 & 2.625 & 1.250 & 13.750 \\
\hline $\mathrm{C}_{2}$ & 3.250 & 0.000 & 1.250 & 3.500 & 1.375 & 2.750 & 3.125 & 15.250 \\
\hline$C_{3}$ & 1.500 & 1.250 & 0.000 & 2.250 & 3.250 & 3.000 & 2.750 & 14.000 \\
\hline$C_{4}$ & 2.500 & 2.125 & 1.375 & 0.000 & 1.500 & 3.500 & 2.000 & 13.000 \\
\hline$C_{5}$ & 2.250 & 2.000 & 3.500 & 2.125 & 0.000 & 3.000 & 1.500 & 14.375 \\
\hline$C_{6}$ & 2.250 & 2.250 & 1.750 & 3.500 & 2.125 & 0.000 & 1.875 & 13.750 \\
\hline$C_{7}$ & 3.125 & 2.250 & 3.000 & 1.750 & 2.500 & 1.375 & 0.000 & 14.000 \\
\hline sum & 14.875 & 13.500 & 12.125 & 16.375 & 12.500 & 16.250 & 12.500 & 16.375 \\
\hline
\end{tabular}

Table B2. Direct-influence matrix $\boldsymbol{D}$

\begin{tabular}{ccccccccc}
\hline Criteria & $C_{1}$ & $C_{2}$ & $C_{3}$ & $C_{4}$ & $C_{5}$ & $C_{6}$ & $C_{7}$ & sum \\
\hline$C_{1}$ & 0.0000 & 0.2214 & 0.0763 & 0.1985 & 0.1069 & 0.1603 & 0.0763 & 0.8397 \\
\hline$C_{2}$ & 0.1985 & 0.0000 & 0.0763 & 0.2137 & 0.0840 & 0.1679 & 0.1908 & 0.9313 \\
\hline$C_{3}$ & 0.0916 & 0.0763 & 0.0000 & 0.1374 & 0.1985 & 0.1832 & 0.1679 & 0.8550 \\
\hline$C_{4}$ & 0.1527 & 0.1298 & 0.0840 & 0.0000 & 0.0916 & 0.2137 & 0.1221 & 0.7939 \\
\hline$C_{5}$ & 0.1374 & 0.1221 & 0.2137 & 0.1298 & 0.0000 & 0.1832 & 0.0916 & 0.8779 \\
\hline$C_{6}$ & 0.1374 & 0.1374 & 0.1069 & 0.2137 & 0.1298 & 0.0000 & 0.1145 & 0.8397 \\
\hline$C_{7}$ & 0.1908 & 0.1374 & 0.1832 & 0.1069 & 0.1527 & 0.0840 & 0.0000 & 0.8550 \\
\hline sum & 0.9084 & 0.8244 & 0.7405 & 1.0000 & 0.7634 & 0.9924 & 0.7634 & \\
\hline
\end{tabular}

Table B3. Total-influence matrix $\boldsymbol{T}$

\begin{tabular}{ccccccccc}
\hline Criteria & $C_{1}$ & $C_{2}$ & $C_{3}$ & $C_{4}$ & $C_{5}$ & $\mathrm{C}_{6}$ & $C_{7}$ & $r_{i}^{C}$ \\
\hline$C_{1}$ & 0.7646 & 0.8946 & 0.6787 & 1.0128 & 0.7269 & 0.9675 & 0.7203 & 5.77 \\
\hline$C_{2}$ & 0.9995 & 0.7745 & 0.7367 & 1.0929 & 0.7688 & 1.0399 & 0.8615 & 6.27 \\
\hline$C_{3}$ & 0.8524 & 0.7836 & 0.6322 & 0.9637 & 0.8190 & 0.9900 & 0.7946 & 5.84 \\
\hline$C_{4}$ & 0.8552 & 0.7879 & 0.6579 & 0.7999 & 0.6876 & 0.9609 & 0.7188 & 5.47 \\
\hline$C_{5}$ & 0.9040 & 0.8371 & 0.8185 & 0.9847 & 0.6666 & 1.0146 & 0.7552 & 5.98 \\
\hline$C_{6}$ & 0.8779 & 0.8236 & 0.7056 & 1.0133 & 0.7462 & 0.8240 & 0.7435 & 5.73 \\
\hline$C_{7}$ & 0.9334 & 0.8393 & 0.7843 & 0.9479 & 0.7850 & 0.9197 & 0.6560 & 5.87 \\
\hline$d_{i}^{C}$ & 6.19 & 5.74 & 5.01 & 6.82 & 5.20 & 6.72 & 5.25 & \\
\hline
\end{tabular}


Table B4. Dimension matrix $\boldsymbol{T}_{D}$ and cause-effect analysis of dimensions

\begin{tabular}{cccccccccc}
\hline & $D_{1}$ & $D_{2}$ & $D_{3}$ & $D_{4}$ & $D_{5}$ & $r_{i}^{D}$ & $d_{i}^{D}$ & $r_{i}^{D}+d_{i}^{D}$ & $r_{i}^{D}-d_{i}^{D}$ \\
\hline$D_{1}$ & 0.858 & 0.880 & 0.748 & 1.004 & 0.791 & 4.281 & 4.286 & 8.567 & -0.005 \\
\hline$D_{2}$ & 0.820 & 0.763 & 0.753 & 0.975 & 0.757 & 4.069 & 4.271 & 8.340 & -0.202 \\
\hline$D_{3}$ & 0.871 & 0.902 & 0.667 & 1.015 & 0.755 & 4.208 & 3.699 & 7.907 & 0.510 \\
\hline$D_{4}$ & 0.851 & 0.859 & 0.746 & 0.824 & 0.744 & 4.024 & 4.737 & 8.761 & -0.713 \\
\hline$D_{5}$ & 0.886 & 0.866 & 0.785 & 0.920 & 0.656 & 4.113 & 3.702 & 7.815 & 0.411 \\
\hline$d_{i}^{D}$ & 4.286 & 4.271 & 3.699 & 4.737 & 3.702 & & & & \\
\hline
\end{tabular}

Table B5. Normalized dimensional matrix $\boldsymbol{T}_{D}^{N}$

\begin{tabular}{cccccc}
\hline Dimensions & $D_{1}$ & $D_{2}$ & $D_{3}$ & $D_{4}$ & $D_{5}$ \\
\hline$D_{1}$ & 0.200 & 0.206 & 0.175 & 0.234 & 0.185 \\
\hline$D_{2}$ & 0.201 & 0.188 & 0.185 & 0.240 & 0.186 \\
\hline$D_{3}$ & 0.207 & 0.214 & 0.158 & 0.241 & 0.179 \\
\hline$D_{4}$ & 0.211 & 0.214 & 0.185 & 0.205 & 0.185 \\
\hline$D_{5}$ & 0.215 & 0.211 & 0.191 & 0.224 & 0.159 \\
\hline
\end{tabular}

Table B6. Un-weighted super-matrix $\boldsymbol{W}$

\begin{tabular}{cccccccc}
\hline Criteria & $C_{1}$ & $C_{2}$ & $C_{3}$ & $C_{4}$ & $C_{5}$ & $C_{6}$ & $C_{7}$ \\
\hline$C_{1}$ & 0.461 & 0.563 & 0.521 & 0.520 & 0.519 & 0.516 & 0.527 \\
\hline$C_{2}$ & 0.539 & 0.437 & 0.479 & 0.480 & 0.481 & 0.484 & 0.473 \\
\hline$C_{3}$ & 0.401 & 0.403 & 0.396 & 0.451 & 0.454 & 0.410 & 0.453 \\
\hline$C_{4}$ & 0.599 & 0.597 & 0.604 & 0.549 & 0.546 & 0.590 & 0.547 \\
\hline$C_{5}$ & 1.000 & 1.000 & 1.000 & 1.000 & 1.000 & 1.000 & 1.000 \\
\hline$C_{6}$ & 1.000 & 1.000 & 1.000 & 1.000 & 1.000 & 1.000 & 1.000 \\
\hline$C_{7}$ & 1.000 & 1.000 & 1.000 & 1.000 & 1.000 & 1.000 & 1.000 \\
\hline
\end{tabular}

Table B7. DEMATEL-weighted super-matrix $\boldsymbol{W}^{D W}$

\begin{tabular}{cccccccc}
\hline Criteria & $C_{1}$ & $C_{2}$ & $C_{3}$ & $C_{4}$ & $C_{5}$ & $\mathrm{C}_{6}$ & $C_{7}$ \\
\hline$C_{1}$ & 0.092 & 0.113 & 0.105 & 0.105 & 0.107 & 0.109 & 0.113 \\
\hline$C_{2}$ & 0.108 & 0.087 & 0.096 & 0.096 & 0.100 & 0.102 & 0.102 \\
\hline$C_{3}$ & 0.083 & 0.083 & 0.074 & 0.085 & 0.097 & 0.088 & 0.096 \\
\hline$C_{4}$ & 0.123 & 0.123 & 0.114 & 0.103 & 0.117 & 0.126 & 0.115 \\
\hline$C_{5}$ & 0.175 & 0.175 & 0.185 & 0.185 & 0.158 & 0.185 & 0.191 \\
\hline$C_{6}$ & 0.234 & 0.234 & 0.240 & 0.240 & 0.241 & 0.205 & 0.224 \\
\hline$C_{7}$ & 0.185 & 0.185 & 0.186 & 0.186 & 0.179 & 0.185 & 0.159 \\
\hline
\end{tabular}


Table B8. The stable limiting super-matrix by raising power $z$ of $\lim _{z \rightarrow \infty}\left(\boldsymbol{W}^{D W}\right)^{z}$

\begin{tabular}{cccccccc}
\hline Criteria & $C_{1}$ & $C_{2}$ & $C_{3}$ & $C_{4}$ & $C_{5}$ & $C_{6}$ & $C_{7}$ \\
\hline$C_{1}$ & 0.107 & 0.107 & 0.107 & 0.107 & 0.107 & 0.107 & 0.107 \\
\hline$C_{2}$ & 0.100 & 0.100 & 0.100 & 0.100 & 0.100 & 0.100 & 0.100 \\
\hline$C_{3}$ & 0.088 & 0.088 & 0.088 & 0.088 & 0.088 & 0.088 & 0.088 \\
\hline$C_{4}$ & 0.118 & 0.118 & 0.118 & 0.118 & 0.118 & 0.118 & 0.118 \\
\hline$C_{5}$ & 0.179 & 0.179 & 0.179 & 0.179 & 0.179 & 0.179 & 0.179 \\
\hline$C_{6}$ & 0.228 & 0.228 & 0.228 & 0.228 & 0.228 & 0.228 & 0.228 \\
\hline$C_{7}$ & 0.179 & 0.179 & 0.179 & 0.179 & 0.179 & 0.179 & 0.179 \\
\hline
\end{tabular}

Kao-Yi SHEN received his Bachelor and Master degrees in Industrial Engineering from the Tunghai University in 1992 and 1998 respectively; and in 2002, he received the PhD degree in Business Administration from the Chengchi University in Taiwan. He worked as a senior analyst in the venture capital industry, and he also worked as a Marketing Manager and Head of Project Management in a Taiwan-based IT company. He developed more than 10 IT products, and he also owned several patents in TV-signals related applications in Taiwan, US, and China. He currently works as an Associate Professor at the Department of Banking and Finance in Chinese Culture University (SCE) in Taiwan, and he has published several papers to solve financial problems by using soft computing and MCDM methods in the journals like Knowledge-based Systems, International Journal of Fuzzy Systems, etc.

Gwo-Hshiung TZENG. In 1967, he received the Bachelor's degree in Business Management from the Tatung Institute of Technology (now Tatung University), Taiwan; in 1971, he received the Master's degree in Urban Planning from Chung Hsing University (now Taipei University), Taiwan; and in 1977, he received the $\mathrm{PhD}$ degree course in management science from Osaka University, Osaka, Japan. He was an Associate Professor at Chiao Tung University, Taiwan (1977-1981), a Research Associate at Argonne National Laboratory (July 1981 - January 1982), a Visiting Professor in the Department of Civil Engineering at University of Maryland, College Park (August 1989 - August 1990), a Visiting Professor in the Department of Engineering and Economic System, Energy Modeling Forum at Stanford University (August 1997 - August 1998), a Professor at Chaio Tung University (1981-2003), and a Chair Professor at Chiao Tung University. He currently works at a Distinguished Chair Proffesor at the Graduate Institute of Urban Planning of Collegue of Public Affairs, National Taipei University. His research interests include statistics, multivariate analysis, network, routing and scheduling, multiple criteria decision making, fuzzy theory, hierarchical structure analysis for applying to technology management, energy, environment, transportation systems, transportation investment, logistics, location, urban planning, tourism, technology management, electronic commerce, global supply chain, etc. 